\title{
Prophylaxis of post-ERCP pancreatitis: European Society of Gastrointestinal Endoscopy (ESGE) Guideline - Updated June 2014
}

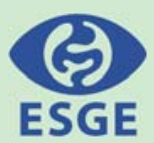

Authors

Institutions
Jean-Marc Dumonceau' ${ }^{1}$, Angelo Andriulli ${ }^{2}$, B. Joseph Elmunzer ${ }^{3}$, Alberto Mariani ${ }^{4}$, Tobias Meister ${ }^{5}$, Jacques Deviere ${ }^{6}$, Tomasz Marek ${ }^{7}$, Todd H. Baron ${ }^{8}$, Cesare Hassan ${ }^{9}$, Pier A. Testoni ${ }^{4}$, Christine Kapral ${ }^{10}$

Institutions are listed at the end of article.
Bibliography

Dol http://dx.doi.org/

10.1055/s-0034-1377875

Published online: 22.8 .2014

Endoscopy 2014; 46: 799-815

(c) Georg Thieme Verlag KG

Stuttgart · New York

ISSN 0013-726X

Corresponding author

Jean-Marc Dumonceau,

\section{PhD}

Gedyt Endoscopy Center Beruti 2347 (C1117AAA)

Buenos Aires

Argentina

Fax: +52886100

jmdumonceau@hotmail.com

This Guideline is an official statement of the European Society of Gastrointestinal Endoscopy (ESGE). It addresses the prophylaxis of post-endoscopic retrograde cholangiopancreatography (post-ERCP) pancreatitis.

Main recommendations

1 ESGE recommends routine rectal administration of $100 \mathrm{mg}$ of diclofenac or indomethacin immediately before or after ERCP in all patients without contraindication. In addition to this, in the case of high risk for post-ERCP pancreatitis (PEP), the placement of a 5-Fr prophylactic pancreatic stent should be strongly considered. Sublingually administered glyceryl trinitrate or 250 $\mu \mathrm{g}$ somatostatin given in bolus injection might be considered as an option in high risk cases if nonsteroidal anti-inflammatory drugs (NSAIDs) are contraindicated and if prophylactic pancreatic stenting is not possible or successful.

2 ESGE recommends keeping the number of cannulation attempts as low as possible.

3 ESGE suggests restricting the use of a pancreatic guidewire as a backup technique for biliary cannulation to cases with repeated inadvertent cannulation of the pancreatic duct; if this method is used, deep biliary cannulation should be

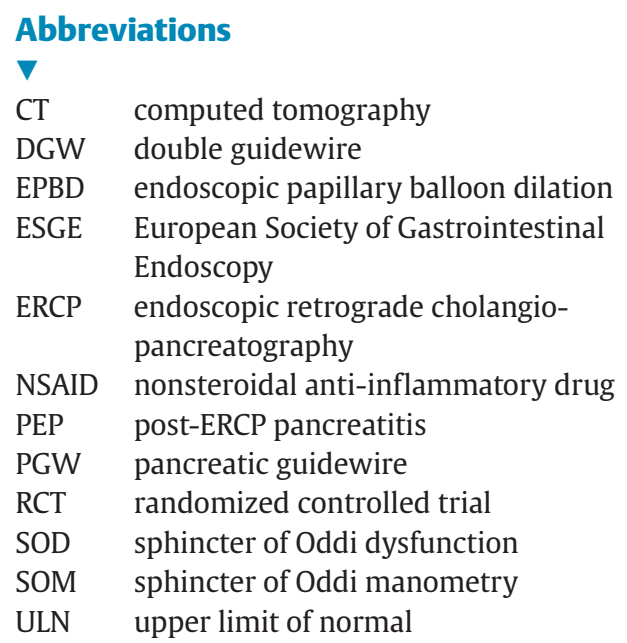

attempted using a guidewire rather than the contrast-assisted method and a prophylactic pancreatic stent should be placed.

4 ESGE suggests that needle-knife fistulotomy should be the preferred precut technique in patients with a bile duct dilated down to the papilla. Conventional precut and transpancreatic sphincterotomy present similar success and complication rates; if conventional precut is selected and pancreatic cannulation is easily obtained, ESGE suggests attempting to place a small-diameter (3-Fr or 5-Fr) pancreatic stent to guide the cut and leaving the pancreatic stent in place at the end of ERCP for a minimum of $12-24$ hours.

4 ESGE does not recommend endoscopic papillary balloon dilation as an alternative to sphincterotomy in routine ERCP, but it may be advantageous in selected patients; if this technique is used, the duration of dilation should be longer than 1 minute.

\section{Introduction \\ $\nabla$}

The Guideline on prophylaxis of post-ERCP pancreatitis (PEP) issued by the European Society of Gastrointestinal Endoscopy (ESGE) in 2010 aimed to provide a qualified basis for gastrointestinal endoscopists to take measures to minimize the incidence and severity of PEP [1]. Shortly before the publication of the ESGE Guideline, nonsteroidal anti-inflammatory drugs (NSAIDs) were reportedly rarely used in clinical practice for prevention of PEP (16\% of respondents to a survey performed in June 2009), and this was attributed by survey participants to the lack of sufficient data [2]. Similarly, in an Austrian nationwide ERCP survey, PEP prophylaxis was administered 
in only $4.0 \%$ of patients in 2010 and in $7.0 \%$ of patients in 2011 [3]. A more recent survey from the UK found that the proportion of endoscopists using NSAIDs had increased to 34.6\% in 2012 [4]. Obviously, prophylactic measures against PEP are still greatly underused in daily clinical practice. At the same time, PEP is still the most frequent and severe complication encountered following ERCP.

New evidence that has become available since the publication of the ESGE Guideline in 2010 is discussed in the present update and new recommendations are issued.

\section{Methods}

$\nabla$

ESGE commissioned this update of the Guideline on prevention of PEP. Methods similar to those used in the previous Guideline were applied [1]. A literature search of PubMed/MEDLINE, a search using the Cochrane Library, Embase, and the internet was performed to identify publications since 2009 on this topic. The search focused on fully published prospective studies, particularly randomized controlled trials (RCTs) and meta-analyses. Retrospective analyses and pilot studies were also included if they addressed topics not covered in the prospective studies.

Thereafter, the commissioned authors met once and subsequently developed the updated Guideline. The Guideline committee chairs (C.K., J.M.D.) worked with the subgroup leaders (C.K., T.M., A.A., T.M., P.T., T.B., J.M.D.) who developed draft proposals that were distributed and reviewed electronically. In May 2014, a draft prepared by C.K. and J.M.D. was sent to all group members. After agreement on a final version, the manuscript was sent to all individual ESGE members and individual ESGE member societies, and was reviewed by two experts selected by the ESGE Governing Board. After incorporation of comments, the manuscript was then sent to the journal Endoscopy for publication. The final wording of the Guideline document was agreed by all commissioned authors.

\section{Definitions \\ $\nabla$ \\ - Statement 2010: \\ None. \\ - Statement 2014:}

Two definitions of PEP may currently be used, neither of these being ideal in the setting of PEP: the consensus definition and grading of severity of PEP according to Cotton et al. and the more recent revised Atlanta international consensus definition and classification of acute pancreatitis.

\section{Background:}

The consensus definition and grading of severity of PEP developed by Cotton et al. has been used for $>20$ years [5]. It has allowed standardized reporting of the incidence and severity of PEP. Post-ERCP pancreatitis was originally defined as "clinical pancreatitis with amylase at least three times the upper limit of normal at more than 24 hours after the procedure, requiring hospital admission or a prolongation of planned admission." Various modifications were introduced by Freeman et al. who proposed using lipase as a possible alternative to amylase and defining clinical pancreatitis as "new or worsened abdominal pain," hence taking into account patients who undergo ERCP in the setting of acute pancreatitis or of a flare of chronic pancreatitis [6]. The grading system for the severity of PEP by the consensus defini- tion is not ideal as it is mainly based on the length of hospitalization.

\section{New information since 2009:}

The Atlanta classification of acute pancreatitis was updated in 2012 [7]. Although this classification provides clear definitions to classify acute pancreatitis, its limitations include the fact that it was not primarily developed to define PEP. Also, the benefit of a contrast-enhanced computed tomography (CT) scan has not been demonstrated in the setting of PEP (contrast-enhanced CT scan is required if abdominal pain suggests strongly that acute pancreatitis is present, but the serum amylase and/or lipase activity is less than three times the upper limit of normal [ULN]). According to this classification, the diagnosis of PEP requires two of the three following criteria: (i) abdominal pain consistent with acute pancreatitis (acute onset of a persistent, severe, epigastric pain often radiating to the back); (ii) serum lipase or amylase activity at least three times greater than the ULN; and (iii) characteristic findings of acute pancreatitis on contrast-enhanced CT and, less commonly, magnetic resonance imaging or transabdominal ultrasonography. This classification defines three degrees of severity based on the presence or absence of organ failure (plus its duration) and of local or systemic complications.

A prospective study has shown the two definitions presented above to be poorly correlated [8].

The Pancreatitis Across Nations Clinical Research and Education Alliance (PANCREA) has defined four degrees of severity for pancreatitis, based on the presence or absence of complications, both local (necrosis of the pancreas and/or peripancreatic tissue) and systemic (cardiovascular, renal, or respiratory organ failure) [9].

\section{Incidence, risk factors, and severity of PEP $\nabla$}

\subsection{Incidence}

\section{- Statement 2010:}

Pancreatitis is the most frequent complication after ERCP with an incidence of $3.5 \%$ in unselected patients; it is of mild or moderate severity in approximately $90 \%$ of cases.

\section{- Statement 2014:}

No changes.

Background:

Data on incidence rate and severity of PEP were mainly based on a systematic review of 21 prospective studies involving more than 16000 patients [10]. Post-ERCP pancreatitis was found to be the most frequent complication following ERCP, with an incidence of $3.47 \%$ (95\% confidence interval [95\%CI] 3.19\%-3.75\%). Based upon data from studies that have included unselected patients, PEP is mild, moderate, and severe in $45 \%, 44 \%$, and $11 \%$ of cases, respectively. Death occurs in $3 \%$ of cases of PEP $(95 \% \mathrm{CI}$ $1.65 \%-4.51 \%$ ) [10].

\section{New information since 2009:}

Few new data have become available and these have yielded similar results. In an ERCP benchmarking program, PEP was reported to occur in $4.2 \%$ of 13513 unselected procedures [3]. In a retrospective study of 886 procedures, 39 patients (4.4\%) were diagnosed with pancreatitis, of mild moderate, and severe type in $69 \%, 23 \%$, and $8 \%$, respectively [11]. 


\begin{tabular}{|c|c|c|}
\hline & $\begin{array}{l}\text { Adjusted odds ratios ( } 95 \% \text { confi- } \\
\text { dence intervals in parentheses } \\
\text { except where indicated other- } \\
\text { wise) }\end{array}$ & $\begin{array}{l}\text { Pooled incidence of PEP in patients } \\
\text { with vs. those without risk factor }\end{array}$ \\
\hline \multicolumn{3}{|l|}{ Patient-related risk factors } \\
\hline \multicolumn{3}{|l|}{ Definite risk factors } \\
\hline $\begin{array}{l}\text { Suspected sphincter of Oddi } \\
\text { dysfunction (SOD) }\end{array}$ & $1.91(1.37-2.65)$ & $8.6 \%$ vs. $2.5 \%$ \\
\hline Female gender & $3.5(1.1-10.6)$ & $4.0 \%$ vs. $2.1 \% *$ \\
\hline Previous pancreatitis & $2.46(1.93-3.12)$ & $6.7 \%$ vs. $3.8 \%$ \\
\hline \multicolumn{3}{|l|}{ Likely risk factors } \\
\hline Previous PEP & $8.7(3.2-23.86)$ & $30 \%$ vs. $3.5 \%$ \\
\hline Younger age & Range of odds ratios: $1.09-2.87$ & $6.2 \%$ vs. $2.6 \%$ \\
\hline Nondilated extrahepatic bile ducts & & $3.8 \%$ vs. $2.3 \%$ \\
\hline Absence of chronic pancreatitis & $1.87(1.00-3.48)$ & $4.0 \%$ vs. $3.1 \%$ \\
\hline Normal serum bilirubin & $1.89(1.22-2.93)$ & $4.15 \%$ vs. $1.43 \%$ \\
\hline \multicolumn{3}{|l|}{ Procedure-related risk factors } \\
\hline \multicolumn{3}{|l|}{ Definite risk factors } \\
\hline $\begin{array}{l}\text { Cannulation attempts duration } \\
>10 \text { minutes }^{2}\end{array}$ & $1.76(1.13-2.74)$ & $3.8 \%$ vs. $10.8 \%$ \\
\hline Pancreatic guidewire passages $>1$ & $2.77(1.79-4.30)$ & $2.9 \%$ vs. $9.5 \%$ \\
\hline Pancreatic injection & $2.2(1.60-3.01)$ & $3.3 \%$ vs. $1.7 \%$ \\
\hline \multicolumn{3}{|l|}{ Likely risk factors } \\
\hline Precut sphincterotomy ${ }^{3}$ & $2.3(1.4-3.7)$ & $5.3 \%$ vs. $3.1 \%$ \\
\hline Pancreatic sphincterotomy & $3.07(1.64-5.75)$ & $2.6 \%$ vs. $2.3 \%$ \\
\hline Biliary balloon sphincter dilation & $4.51(1.51-13.46)$ & $9.3 \%$ vs. $2.6 \%$ \\
\hline Failure to clear bile duct stones & $3.35(1.33-9.10)$ & $1.7 \%$ vs. $1.6 \%$ \\
\hline Intraductal ultrasound (IDUS) ${ }^{4}$ & $2.41(1.33-4.39)$ & $8.37 \%$ vs. $2.76 \%$ \\
\hline \multicolumn{3}{|c|}{$\begin{array}{l}1 \text { For definite or likely risk factors, adjusted odds ratios are reproduced either from Masci et al. [20] or from included studies that identif } \\
\text { the characteristic as an independent risk factor. Pooled incidences were calculated using figures available in all of the included studies } \\
\text { that provided sufficient data for calculation }[6,16,17,19,21,22,25-27,115,116,177] \text {. (See text for details about included studies) } \\
2 \text { Cannulation attempts of duration }>5 \text { minutes may already increase the incidence of PEP as shown by Halttunen et al. (11.7\% vs. } 2.7 \% \\
\text { for cannulation attempts } \geq 5 \text { minutes vs. }<5 \text { minutes, respectively) [115]. } \\
{ }^{3} \text { Evidence is growing that precut sphincterotomy is not a definite risk factor for PEP by itself, the increased risk of PEP being related to } \\
\text { cannulation efforts that preceded precut [28]. }\end{array}$} \\
\hline
\end{tabular}

Table 1 Independent risk factors for post-endoscopic retrograde cholangiopancreatography (postERCP) pancreatitis (PEP).

\subsection{Risk stratification}

\subsubsection{Hospital and endoscopist volume for ERCP \\ - Statement 2010:}

There is no evidence that hospital ERCP volume has an influence on the incidence of PEP; data about a potential relationship between PEP incidence and endoscopist case volume are conflicting. Low annual case volumes, of endoscopists and centers, are associated with higher ERCP failure rates (Evidence level 2+).

\section{- Statement 2014:}

No changes.

\section{Background:}

Factors that may affect the outcome of ERCP that are specifically related to hospital procedure volume include availability of equipment and adequacy of anesthesia, endoscopic and radiologic support, and nursing assistance. The number of ERCPs performed in many centers is not as high as commonly believed: in three large (regional or national) studies, the median annual number of ERCPs was between 49 and 235 [12-14]. In one large study, the median annual number of ERCPs per endoscopist was 111 and $40 \%$ of endoscopists performed fewer than 50 sphincterotomies/year [15].

Multivariate analyses from two prospective audits performed in England and Italy (66 and 9 centers, respectively) found no significant association between annual hospital volume of ERCPs and incidence of PEP $[16,17]$.
New information since 2009:

A prospective Swedish study of 12718 procedures showed no significant difference among PEP rates in centers with low $(<100$ ERCPs/year), medium, and high (>500 ERCPs/year) volumes [18]. In a prospective multicenter study that included 3635 ERCPs in 11 high volume (>200 ERCPs/year) and 10 low volume centers (median of 275 and 45 ERCPs/year, respectively), there was no significant difference in the incidence of PEP (3.9\% vs. $3.1 \%$ ) [19]. However, these results were confounded because a higher proportion of patients at high risk of PEP was treated in high volume centers. In this study, the PEP rates did not differ significantly between expert and nonexpert operators (3.8\% vs. 5.5\%, respectively; $P=0.34$ ).

\subsubsection{Patient- and procedure-related risk factors for PEP \\ - Statement 2010:}

Independent patient-related and procedure-related risk factors for PEP are listed in $\bullet$ Table 1. Risk factors synergistically increase the risk of PEP (Evidence level 1+).

\section{- Statement 2014:}

Risk factors for PEP, in particular those related to the procedure (cannulation attempts $>10$ minutes and pancreatic guidewire passages $>1$ ) have been updated in $\bullet$ Table 1. Risk factors synergistically increase the risk of PEP.

\section{Background:}

Independent risk factors for PEP were presented in a table based on data from a meta-analysis [20] plus those from five prospec- 
tive, multicenter studies that analyzed potential risk factors for PEP using multivariate analysis $[6,16,17,21,22]$. The list was not exhaustive because not all potential risk factors had been analyzed. For example, ampullectomy is generally considered to be a definitive risk factor for PEP on the basis of several small prospective studies $[23,24]$.

As risk factors for PEP were shown to be independent by multivariate analysis, they might have a cumulative effect. Freeman et al. calculated the adjusted odds ratio (OR) for various combinations of risk factors by using data prospectively collected from about 2000 ERCPs: the highest risk of PEP (42\%) was found for female patients with a normal serum bilirubin level, suspected sphincter of Oddi dysfunction (SOD), and difficult biliary cannulation [21].

\section{New information since 2009:}

Suspected or known dysfunction of the sphincter of Oddi, female gender, younger age, and previous history of pancreatitis are well-known independent risk factors for PEP. A recent prospective study confirmed these findings [25]. In a large ERCP series that included 11497 procedures, SOD was confirmed as an independent risk factor [26]. Recently, in a Swedish case-control study of 12718 ERCP procedures, independent risk factors were young age, female gender, prolonged procedure time, and elective ERCP; whereas rendezvous procedures reduced the risk of PEP [18]. Another prospective multicenter study confirmed independent procedure- and patient-related risk factors for $\operatorname{PEP}(>10$ attempts to cannulate the papilla of Vater, OR 14.9; previous PEP, OR 8.7; precut, OR 3.1; pancreatic duct cannulation, OR 2.1) [19]. Some of these predictors were confirmed in two other studies $[25,27]$. However, needle-knife sphincterotomy was found not to be an independent risk factor for PEP $[3,25,28]$.

The role of intraductal ultrasound as a risk factor for PEP remains unclear but this factor was identified by multivariate analysis (OR $2.41, P=0.004)$ in a retrospective analysis of 2364 ERCP procedures [29].

No new data have become available regarding the synergistic effect of risk factors for PEP.

\subsection{Prediction of PEP}

\section{- Statement 2010:}

Serum amylase values less than 1.5 times the ULN, obtained at 2 4 hours post-ERCP, almost exclude PEP; values more than 3 or 5 times the ULN at 4-6 hours post-ERCP have increasing positive predictive values for PEP (Evidence level $2+$ ). It is recommended that serum amylase be determined in patients to be discharged on the day of ERCP; patients with amylase values less than 1.5 times the ULN can be discharged without concern about risk of PEP (Recommendation grade B).

\section{- Statement 2014:}

Serum amylase or lipase values less than 1.5 and 4 times the ULN, respectively, obtained at $2-4$ hours post-ERCP have a very high negative predictive value for PEP (Evidence level 2+). ESGE suggests testing serum amylase or lipase $2-6$ hours after ERCP in patients presenting with pain and who are to be discharged on the day of ERCP; patients with amylase or lipase values less than 1.5 and 4 times the ULN, respectively, can be discharged without concern about risk of PEP (Recommendation grade B).

\section{Background:}

The recommendations were based on five studies that reported similar predictive values based on serum amylase levels obtained 2 to 6 hours following ERCP. In one study of PEP [30], lipase values at a cutoff of 4 times the ULN had a negative and positive predictive value for PEP of $99 \%$ and $15 \%$, respectively.

\section{New information since 2009:}

Two studies confirmed previous findings. A prospective study from Brazil that included 300 patients showed that serum hyperamylasemia $<1.5$ times the ULN at 4 hours and $<2$ times the ULN at 12 hours had a negative predictive value of $94 \%$ for the development of PEP [8]. Serum hyperamylasemia following ERCP had a poor positive predictive value for PEP. A retrospective study investigated, in addition to the 4-hour post-ERCP serum amylase level, the impact of having a pancreatogram in predicting PEP among 886 ERCPs [11]; the negative predictive value of serum amylase <2.5 times ULN for moderate or severe PEP was $99.2 \%$ and $100 \%$, in patients who, respectively, did and did not have a pancreatogram.

\section{Pharmacologic agents available for PEP prophylaxis} $\nabla$

\subsection{Introduction}

Post-ERCP pancreatitis appears unavoidable even in the hands of expert endoscopists. Consequently, attempts to reduce the rate of this complication by pharmacological intervention should be pursued. While a few medications have proven effective for preventing PEP, we acknowledge that multiple factors in addition to efficacy influence the decision to issue a clinical recommendation. In particular, the magnitude of benefit, as expressed by the number needed to treat (NNT), the robustness and consistency of supporting RCTs, the safety profile of the medication, its ease of administration, availability, and cost were considered in issuing these recommendations.

\subsection{Drugs with proven efficacy}

\subsubsection{Nonsteroidal anti-inflammatory drugs (NSAIDs)}

\section{- Statement 2010:}

NSAIDs reduce the incidence of PEP; effective PEP prophylaxis has only been demonstrated using $100 \mathrm{mg}$ of diclofenac or indomethacin administered rectally (Evidence level $1++$ ). Routine rectal administration of $100 \mathrm{mg}$ of diclofenac or indomethacin immediately before or after ERCP is recommended (Recommendation grade $\mathrm{A}$ ).

\section{- Statement 2014:}

NSAIDs reduce the incidence of PEP in patients at high as well as low risk for PEP; effective PEP prophylaxis has only been demonstrated using diclofenac or indomethacin administered rectally (Evidence level 1++). ESGE recommends routine rectal administration of $100 \mathrm{mg}$ of diclofenac or indomethacin immediately before or after ERCP in all patients without contraindication (Recommendation grade $\mathrm{A}$ ).

\section{Background:}

Three different meta-analyses pooled data from four RCTs that compared rectally administered diclofenac or indomethacin at a dose of $100 \mathrm{mg}$ vs. placebo [31-33]. Two RCTs evaluated the effect of rectal administration of $100 \mathrm{mg}$ diclofenac immediately after the procedure, while the other two evaluated rectal administration of $100 \mathrm{mg}$ indomethacin immediately before the procedure. Both schedules showed similar results. Patients who were considered to be at high risk for PEP were included in two studies. Overall, PEP occurred in $4.4 \%$ patients in the treatment groups vs. $12.5 \%$ patients in the placebo groups with an estimated pooled relative risk (RR) of 0.36 (95\%CI $0.22-0.60)$, and an NNT to prevent one episode of PEP of 15. The administration of 
Table 2 Meta-analyses published in 2009 or later that assessed the effect of NSAIDs on post-endoscopic retrograde cholangiopancreatography (post-ERCP) pancreatitis (PEP). ${ }^{1}$

\begin{tabular}{|c|c|c|c|c|c|c|}
\hline \multirow{2}{*}{$\begin{array}{l}\text { First author, } \\
\text { year }\end{array}$} & \multirow{2}{*}{$\begin{array}{l}\text { Studies, n } \\
\text { (Patients, n) }\end{array}$} & \multicolumn{2}{|c|}{ PEP incidence } & \multirow{2}{*}{$\begin{array}{l}\text { OR } \\
(95 \% \mathrm{Cl})\end{array}$} & \multirow[t]{2}{*}{ NNT } & \multirow[t]{2}{*}{ Comments } \\
\hline & & NSAIDs & Placebo & & & \\
\hline $\begin{array}{l}\text { Dai, } \\
2009 \text { [31] }\end{array}$ & $\begin{array}{l}6 \\
(1300)\end{array}$ & $8.9 \%$ & $16.8 \%$ & $\begin{array}{l}0.46 \\
(0.32-0.65)\end{array}$ & n.a. & $\begin{array}{l}\text { Inclusion of placebo-controlled RCTs only } \\
\text { (diclofenac or indomethacin administered oral- } \\
\text { ly or rectally). Different ERCP techniques and } \\
\text { criteria for pancreatitis, low number of high risk } \\
\text { patients }\end{array}$ \\
\hline $\begin{array}{l}\text { Ding, } \\
2012 \text { [39] }\end{array}$ & $\begin{array}{l}10 \\
(2269)\end{array}$ & $8.0 \%$ & $13.9 \%$ & $\begin{array}{l}0.57 \\
(0.38-0.86)^{1}\end{array}$ & 17 & $\begin{array}{l}\text { Different NSAIDs (diclofenac, indomethacin, } \\
\text { valdecoxib) and different administration routes } \\
\text { (oral, rectal, intraduodenal, intramuscular and } \\
\text { intravenous) and ERCP techniques; moderate } \\
\text { and severe PEP also reduced. } \\
\text { Moderate/severe PEP: RR } 0.46(0.28-0.38) \text {; } \\
\text { NNT, } 34\end{array}$ \\
\hline $\begin{array}{l}\text { Yaghoobi, } \\
2013 \text { [40] }\end{array}$ & $\begin{array}{l}4 \\
(1470)\end{array}$ & $5.1 \%$ & $10.3 \%$ & $\begin{array}{l}0.49 \\
(0.34-0.71)\end{array}$ & 20 & $\begin{array}{l}\text { Only rectal NSAIDs; } \\
\text { significant decrease of PEP incidence in both } \\
\text { high risk and low risk patients, moderate and } \\
\text { severe PEP also reduced. } \\
\text { Moderate/severe PEP: RR } 0.45(0.24-0.83)\end{array}$ \\
\hline $\begin{array}{l}\text { Sun, } \\
2013 \text { [41] }\end{array}$ & $\begin{array}{l}7 \\
(1846)\end{array}$ & $6.4 \%$ & $16.0 \%$ & $\begin{array}{l}0.45 \\
(0.34-0.61)^{1}\end{array}$ & n.a. & $\begin{array}{l}\text { Only rectal NSAIDs; } \\
\text { both diclofenac and indomethacin effective, } \\
\text { significant in both high risk and average-risk } \\
\text { cohorts, moderate and severe PEP reduced. } \\
\text { Mild PEP: RR } 0.54(0.35-0.83) \\
\text { Moderate/severe PEP: RR } 0.39(0.22-0.70)\end{array}$ \\
\hline $\begin{array}{l}\text { Yuhara, } \\
2014 \text { [42] }\end{array}$ & $\begin{array}{l}9 \\
(1981)\end{array}$ & $7.8 \%$ & $16.0 \%$ & $\begin{array}{l}0.55 \\
(0.43-0.72)^{*}\end{array}$ & n.a. & $\begin{array}{l}\text { Inclusion of RCTs testing rectal, oral, intra- } \\
\text { muscular and intravenous NSAIDs (diclofenac, } \\
\text { indomethacin). No significant effect on PEP } \\
\text { with intramuscular administration. }\end{array}$ \\
\hline $\begin{array}{l}\text { Sethi, } \\
2014 \text { [43] }\end{array}$ & $\begin{array}{l}7 \\
(2133)\end{array}$ & $6.6 \%$ & $15.1 \%$ & $\begin{array}{l}0.44 \\
(0.34-0.57)^{1}\end{array}$ & 11 & $\begin{array}{l}\text { Only rectal NSAIDs; } \\
\text { no difference between diclofenac and indo- } \\
\text { methacin, no difference between timing (pre- } \\
\text { and post-ERCP). } \\
\text { Relative risk in low risk and high risk patients, } \\
\text { respectively: } 0.42(0.26-0.66) \text { and } 0.45(0.31 \text { - } \\
0.65) \text {. }\end{array}$ \\
\hline
\end{tabular}

NSAIDs, nonsteroidal anti-inflammatory drugs; OR, odds ratio; Cl, confidence interval; NNT, number needed to treat; n.a., not available; RCT, randomized controlled trial; RR, relative risk.

${ }^{1}$ Risk reduction.

NSAIDs was associated with a similar decrease in the incidence of PEP regardless of risk [33]. No adverse events attributable to NSAIDs were reported.

\section{New information since 2009:}

Despite previous meta-analytical results, NSAIDs were not commonly used by endoscopists in clinical practice: only $16 \%$ of respondents to a survey performed in June 2009, shortly before publication of the ESGE Guideline, used NSAIDs for PEP prophylaxis and this low figure was attributed to the lack of sufficient data [2]. A more recent survey (June 2012) found that the proportion of endoscopists using NSAIDs has increased to $35 \%$ [4].

In a multicenter RCT [34], patients at high risk for PEP received either a single dose of rectal indomethacin or of placebo immediately after ERCP. A total of 602 patients were enrolled, including $82 \%$ with a clinical suspicion of SOD and $82 \%$ who received prophylactic pancreatic stenting based on the high risk of PEP. PostERCP pancreatitis developed in $9.2 \%$ vs. $16.9 \%$ of patients in the indomethacin vs. placebo group, respectively $(P=0.005)$. Of note, moderate-to-severe PEP was less frequent in the indomethacin vs. placebo group ( $4.4 \%$ vs. $8.8 \%$, respectively; $P=0.03$ ). The benefit of $100 \mathrm{mg}$ rectal indomethacin was also confirmed in an RCT that included 228 patients but the results were not significantly different from placebo, likely owing to the small sample size [35]. A lower dosage of diclofenac, either $50 \mathrm{mg}$ or $25 \mathrm{mg}$ in patients weighing $\geq 50 \mathrm{~kg}$ or $<50 \mathrm{~kg}$, respectively, was compared with placebo in a small RCT from Japan: the PEP incidence was $3.9 \%$ vs. $18.9 \%$ in the diclofenac vs. the control group, respectively ( $P=$ 0.017) [36]. A small RCT of 80 patients demonstrated a nonsignificant trend toward benefit associated with the combination of intramuscular diclofenac and intensive intravenous fluid administration [37]. On the other hand, it seems that selective cyclooxygenase-2 inhibitor (coxib) administration is ineffective, as shown by an RCT that included 371 patients where intravenous valdecoxib or glyceryl trinitrate (GTN) patch were compared with placebo: the incidence of PEP was similar in all treatment groups $(10 \%, P=0.986)$ [38].

Six meta-analyses published between 2009 and 2014 ( $\odot$ Table 2) compared NSAIDs vs. placebo administration for prevention of PEP, and all of them concordantly showed the benefit of NSAIDs in preventing either mild or moderate/severe PEP. The NNT figures, reported in the majority of these studies, have varied from 11 to $34[31,39-43]$. 
In a post hoc analysis of an RCT of NSAIDs vs. placebo for PEP prophylaxis, administration of rectal NSAIDs alone was more effective and less costly than prophylactic pancreatic stent placement alone or combined with rectal NSAIDs [44]. However, the authors cautioned that these findings should not change current clinical practice because their post hoc observational study did not produce the same quality of evidence as their RCT, which supported the use of indomethacin in addition to prophylactic pancreatic stenting in high risk cases [34].

\subsection{Possibly effective drugs \\ 5.3.1. Somatostatin and octreotide \\ - Statement 2010:}

Based on an ad hoc meta-analysis of results from 10 high quality RCTs, somatostatin proved to be ineffective in preventing PEP (Evidence level $1++$ ). We do not recommend universal administration of prophylactic somatostatin in average-risk patients undergoing ERCP (Recommendation grade A). Administration of somatostatin might be more efficacious using specific dose schedules, but caution is needed when interpreting the results of subgroup analyses as they often exaggerate differences between treatments in RCTs.

Octreotide administration did not affect the overall incidence of PEP when data from eight high quality trials were pooled (Evidence level $1++)$. Prophylaxis with octreotide is not recommended (Recommendation grade A). In future studies the efficacy of prophylactic administration of octreotide should be evaluated using a dose greater than or equal to $0.5 \mathrm{mg}$.

\section{- Statement 2014:}

Some meta-analytical results seem to support the benefit of somatostatin and octreotide for averting PEP but their clinical use cannot be recommended except in well selected cases, owing to discordant data from different routes or dosages and the excessively high NNT values (Recommendation grade A).

\section{Background:}

Three meta-analyses assessed the effect of somatostatin/octreotide for PEP prophylaxis before the 2010 ESGE Guideline publication [1]; an updated meta-analysis of high quality RCTs (Jadad score $>3$ ) was performed for writing the ESGE Guideline. Respectively, 10 and 8 RCTs were included for assessing somatostatin and octreotide. Overall, the updated meta-analysis found no significant reduction of PEP incidence with somatostatin vs. placebo (OR $0.57 ; 95 \% \mathrm{CI} 0.32-1.03$ ) or with octreotide vs. placebo (OR $0.73 ; 95 \% \mathrm{CI}, 0.41-1.30$ ). However, subgroup analyses suggested that some dosages or administration schedules might be associated with a protective effect against PEP.

\section{New information since 2009:}

A meta-analysis that compared octreotide vs. placebo (18 RCTs, 3171 patients) found no significant difference in PEP incidence (OR 0.77; 95\%CI 0.56-1.05) [45]. However, at post hoc subgroup analysis, dosage seemed to have an impact: when the compound was given at a dose $\geq 0.5 \mathrm{mg}$ ( 6 RCTs; 1470 patients) the OR for developing PEP dropped to 0.45 (95\%CI 0.28-0.73; NNT=25), whereas the agent proved ineffective at a dosage $<0.5 \mathrm{mg}$. Other subgroup analyses of octreotide administration that assessed the route (intravenous vs. subcutaneous) and the schedule (before or after ERCP) were inconclusive.

A second meta-analysis assessed the effect of somatostatin (10 RCTs) and of octreotide (7 RCTs) in a total of 3818 patients [46]. Overall, somatostatin reduced the risk of PEP (RR 0.52; 95\%CI $0.30-0.90$ ), while octreotide was not effective (RR $0.86 ; 95 \% \mathrm{CI}$ $0.45-1.63)$. Subgroup analyses suggested that higher doses of so- matostatin ( $3 \mathrm{mg}$ given as an infusion over 12 hours) or lower doses $(250 \mu \mathrm{g})$ given as bolus injection may be most efficacious, especially for the subgroup of patients at relatively higher risk for PEP, i.e., those undergoing pancreatic duct injection (OR 0.35 ; $95 \% \mathrm{CI} 0.15-0.82$ ) and biliary sphincterotomy (OR 0.33; $95 \% \mathrm{CI} 0.16-0.70)$. With regard to octreotide, subgroup analysis showed a protective effect when administered at high dose (OR 0.42; 95\%CI 0.20-0.90).

More recently, two RCTs compared the effect of somatostatin vs. placebo for PEP prophylaxis. In one RCT, the efficacy of somatostatin alone could not be assessed because the treatment group received somatostatin plus diclofenac [47]; the other RCT found that high dose somatostatin was associated with a reduction of post-ERCP hyperamylasemia, but not incidence of PEP [48].

\subsubsection{Protease inhibitors}

\section{- Statement 2010:}

Prophylaxis with gabexate or ulinastatin does not reduce the incidence of PEP (Evidence 1++). Neither drug is recommended for prophylaxis of PEP (Recommendation grade A).

\section{- Statement 2014:}

Some meta-analytical results seem to support the benefit of gabexate and ulinastatin at high doses for averting PEP but their clinical use cannot be recommended owing to the discordance of the data. A novel protease inhibitor, nafamostat, is likely effective for preventing PEP in patients at low risk of PEP but not in high risk patients.

\section{Background:}

Gabexate for PEP prophylaxis has been evaluated in six high quality RCTs [49-54]; when the results were pooled, no significant difference was found between the control and treatment groups. Ulinastatin for PEP prophylaxis has been compared with placebo (two RCTs) and with gabexate (two RCTs), with contradictory results [55-58]. Nafamostat is a novel protease inhibitor that inhibits trypsin, a proteolytic enzyme considered to play an initial role in the pathogenesis of pancreatitis; compared with gabexate its half-life is 20 times longer and its potency 10 to 100 times greater.

\section{New information since 2009:}

Four meta-analyses assessed the efficacy of protease inhibitors for PEP prophylaxis [42,59-61]. Subgroup analysis of 8 high quality (Jadad score >3) RCTs on gabexate administration showed that the agent was not associated with a decreased risk of PEP (RR 0.64; 95\%CI 0.36-1.13) and there was great heterogeneity among the studies. Subgroup analysis of 6 ulinastatin RCTs showed the agent was not associated with a decreased risk of PEP in either high quality studies (RR 0.65 ; $95 \% \mathrm{CI} 0.33-1.30$ ) or low quality studies (RR 0.75; 95\%CI 0.49-1.16).

The question of drug dosage was addressed in one meta-analysis: when ulinastatin was administered at sufficient doses ( $\geq 150000$ units), it averted PEP (OR 0.39; 95\%CI 0.19-0.81; NNT 6); in a similar fashion, gabexate was effective at either slow infusion of high dose ( $\geq 150000$ units) (OR 0.44; 95\%CI 0.25-0.79; NNT 7) or rapid infusion of low dose (OR 0.37; 95\%CI 0.20-0.69; NNT 6) [61].

The benefit of nafamostat has been assessed in a meta-analysis that pooled data from 5 RCTs and 2678 patients [42]. This agent lowered the incidence of PEP (RR 0.47; 95\%CI $0.33-0.67$ ). All three RCTs available as full text found nafamostat to be effective in low risk patients but not in high risk patients [62 -64]. When the results observed for high risk patients in the three RCTs were pooled, PEP incidence was not statistically different in the treat- 
ment vs. the placebo group ( $8.9 \%$ [32/358] vs. $13.1 \%$ [37/283], respectively; $P=0.12$ ).

\subsubsection{Drugs influencing sphincter of Oddi pressure - Statement 2010:}

Nitroglycerin reduces the incidence of PEP; however, when administered transdermally, it is ineffective (Evidence grade $1++$ ). Side effects such as transient hypotension and headache may occur. We do not recommend the routine use of nitroglycerin for prophylaxis of PEP (Recommendation grade A).

There is no evidence that ... drugs reducing sphincter of Oddi pressure (other than nitroglycerin) [namely, botulinum toxin, epinephrine, lidocaine, and nifedipine] ... reduce the incidence of PEP ... [cf. section 5.4 below].

\section{- Statement 2014:}

Glyceryl trinitrate (GTN) may be effective in preventing PEP when administered sublingually. Topical epinephrine may be effective to prevent PEP in purely diagnostic ERCP. ESGE does not recommend the routine use of GTN or of epinephrine for PEP prophylaxis. No changes concerning botulinum toxin, lidocaine, and nifedipine.

\section{Background:}

The influence of GTN on the incidence of PEP was evaluated in two meta-analyses that pooled data from 5 RCTs involving 1662 patients [65, 66]. Both meta-analyses showed an overall significant reduction of PEP with an RR of 0.61 (95\%CI $0.44-0.86$ ) and an NNT of 26. In the majority of the patients, GTN was administered transdermally. In a subgroup analysis, transdermal GTN failed to show a significant reduction of PEP (RR 0.66; 95\%CI $0.43-1.01$ ).

Botulinum toxin [67], epinephrine [68], lidocaine [69], and nifedipine $[70,71]$, were not found to prevent PEP in the corresponding RCTs.

\section{New information since 2009:}

A meta-analysis that pooled data from 8 RCTs (1920 patients) found that GTN decreases PEP incidence compared with placebo (5.9\% vs. 9.8\%, respectively; $P=0.002$ ) [72]. A more recent metaanalysis extended the observation to 12 RCTs (2649 patients) and found again that GTN reduces the overall incidence of PEP (RR $0.67 ; 95 \% \mathrm{CI} 0.52-0.87$ ) but was, however, ineffective in lowering the incidence of moderate to severe PEP (RR $0.70 ; 95 \% \mathrm{CI} 0.42$ 1.15) [73]. The route of GTN administration may influence its effectiveness. Subgroup analyses revealed that sublingual administration of GTN was more effective than transdermal and topical administration (RR 0.47 ; 95\%CI $0.28-0.78$ ).

The prophylactic merit of topical epinephrine $(0.02 \%, 20 \mathrm{~mL}$ sprayed on the papilla) was compared with placebo in diagnostic-only ERCP in two RCTs $[68,74]$. Matsushita et al. originally evaluated spraying of epinephrine onto the papilla in $370 \mathrm{pa}-$ tients undergoing diagnostic ERCP [68]; the incidence of PEP was $0 \%$ in the epinephrine group vs. $2.2 \%$ in the control group (not significant). In the second study, Xu et al. randomized 941 patients to topical epinephrine vs. placebo; the rates of PEP were $1.95 \%$ vs. $6.45 \%$, respectively $(P=0.0086)$ [74]. When the results of the two studies were pooled in a meta-analysis, topical epinephrine proved efficacious in reducing PEP (OR 0.25; 95\%CI $0.06-0.65$; NNT 15) [75]. However, in the two RCTs of epinephrine, only patients with purely diagnostic ERCP were included, no guidewire was initially used, cannulation times were very long, and the definition of PEP was not standard. Based on these shortcomings, routine use of topical epinephrine cannot be recommended for PEP prophylaxis.

\subsubsection{Antibiotics}

\section{- Statement 2010:}

Ceftazidime reduced the incidence of PEP in a single study (Evidence grade 1 - ). Further data are needed before recommending ceftazidime for the prophylaxis of PEP (Recommendation grade C).

\section{- Statement 2014:}

Antibiotics have not been proven effective in PEP prophylaxis; further data are needed (Recommendation grade $\mathrm{C}$ ).

\section{Background:}

In an RCT that tested ceftazidime for prophylaxis of PEP, the incidence of PEP was lower in the treatment than in the control group ( $2.6 \%$ vs. $9.4 \%$, respectively; $P=0.009$ ) [76]. This study was of low methodological quality owing to unclear allocation concealment.

\section{New information since 2009:}

A network meta-analysis ranked antibiotics in fourth position among 16 drugs for the efficacy of PEP prophylaxis (OR 0.46; 95\%CI 0.15-1.07; NNT 21) [75]. However, the difference observed between antibiotics and placebo was not statistically significant, only 254 patients were included in the treatment arms of four RCTs [76-79] included in the meta-analysis (not 1082 as stated in the meta-analysis), and two of these RCTs did not have PEP prophylaxis as their primary study endpoint $[76,78]$.

\subsubsection{Intensive hydration \\ - Statement 2010:}

No statement.

\section{- Statement 2014:}

In a pilot study, intensive hydration seemed to effectively prevent PEP. Large-scale RCTs to establish an evidence-based approach to intensive hydration are needed.

\section{New information since 2009:}

Based on a pilot study in 62 patients, intensive hydration in the periprocedural period with intravenous lactated Ringer's solution appears to reduce PEP incidence [80]. None of the patients who received aggressive hydration developed PEP, compared with $17 \%$ of patients who received standard hydration $(P=$ 0.016). No patients had evidence of volume overload. Two observational studies support this strategy of hydration for attenuating the severity of PEP $[81,82]$.

\subsection{Drugs proven ineffective \\ - Statement 2010:}

There is no evidence that glucocorticoids, drugs reducing sphincter of Oddi pressure (other than nitroglycerin), antioxidants, heparin, interleukin-10, or some anti-inflammatory drugs (other than diclofenac and indomethacin), such as pentoxifylline, semapimod, and the recombinant platelet-activating factor acetylhydrolase, reduce the incidence of PEP (Evidence levels from 1 - to $1++)$. None of these drugs is recommended for PEP prophylaxis (Recommendation grade $\mathrm{A}$ ).

\section{- Statement 2014:}

No change except for GTN and epinephrine (cf. section 5.3.3 above).

\section{Background:}

The efficacy of glucocorticoids for PEP prophylaxis was evaluated in two meta-analyses that included 6 RCTs $[83,84]$; the incidence of PEP was not significantly different in the glucocorticoids vs. the control group ( $11.8 \%$ vs. $10.6 \%$, respectively). Three RCTs that evaluated interleukin-10 have yielded contradictory results [85 - 87]. Subcutaneous heparin was not found to reduce PEP in- 
cidence in 2 RCTs $[88,89]$. Drugs potentially reducing the sphincter of Oddi pressure (other than GTN and topical epinephrine), including botulinum toxin, lidocaine, and nifedipine, have not been found to reduce PEP incidence in RCTs [67, 68,90-92]. Three antioxidant agents, namely allopurinol, N-acetylcysteine, and natural beta-carotene were not found to be effective in preventing PEP in 5 RCTs and one meta-analysis [93-98].

New information since 2009:

Regarding heparin, a meta-analysis that analyzed four clinical trials (including 3 RCTs) with a total of 1438 patients showed no beneficial effect of prophylactic heparin for the prevention of PEP [99]. Regarding antioxidant supplementation, a meta-analysis of 11 RCTs (total, 3010 patients) showed no beneficial effect on the incidence and the severity of PEP [100]. Regarding allopurinol, an RCT found no effect for the prevention of PEP [101]. No new data are available for glucocorticoids, interleukin-10, pentoxifylline, semapimod, and the recombinant platelet-activating factor acetylhydrolase.

\section{Pancreatic stent placement for PEP prophylaxis $\nabla$}

\section{- Statement 2010:}

Prophylactic pancreatic stent placement is recommended to prevent PEP in patients who are at high risk for development of PEP. Short, 5-Fr diameter, plastic pancreatic stents are currently recommended. Passage of the stent from the pancreatic duct should be evaluated within 5 to 10 days of placement and retained stents should be promptly removed endoscopically (Evidence level 1+; Recommendation grade A).

\section{- Statement 2014:}

Prophylactic pancreatic stenting decreases the risk of PEP in high risk and mixed-case groups; it nearly eliminates the risk of severe PEP. 5-Fr pancreatic stents are more efficacious than 3-Fr stents in preventing PEP. ESGE recommends the placement of 5-Fr pancreatic stents in cases at high risk of PEP. Passage of the stent from the pancreatic duct should be evaluated within 5 to 10 days of placement and retained stents should be promptly removed endoscopically (Evidence level $1+$; Recommendation grade A).

\section{Background:}

Two meta-analyses have demonstrated that, in patients at high risk of PEP, prophylactic pancreatic stent placement significantly reduces the incidence of PEP $[102,103]$. The OR was 0.44 (95\%CI $0.24-0.81$ ), with an absolute risk reduction of $12.0 \%$ (95\%CI $3.0-$ 21.0). A multicenter RCT (201 patients) showed a decreased incidence of PEP when prophylactic pancreatic stent placement was performed, regardless of the concomitant occurrence of other known risk factors for PEP (PEP incidence in the stent vs. no-stent group, $3.2 \%$ vs. $13.6 \%$, respectively; $P=0.019$ ) [104]. In these studies, the risk of severe PEP was nearly eliminated following successful placement of a prophylactic pancreatic stent.

Pancreatic stent placement was shown to be cost-effective only in patients at high risk for PEP [105].

\section{New information since 2009:}

A meta-analysis of 14 RCTs with a total of 1541 patients showed a significant reduction in the incidence and the severity of PEP when prophylactic pancreatic stenting was used [106]. In addition, subgroup analysis showed that pancreatic stenting reduced the risk of PEP in high risk and mixed-case groups. In a network meta-analysis, prophylactic pancreatic stenting alone was shown to be less effective than NSAIDs alone, and the combination of
NSAIDs with prophylactic pancreatic stenting did not further reduce the risk of PEP [107].

The ideal stent characteristics for PEP prophylaxis and the optimal duration of stent placement are not definitively known. However, a network meta-analysis showed that the probabilities of 5-Fr and 3-Fr stents being ranked as the most efficacious for the prevention of PEP were $96.8 \%$ vs. 3.1\%, respectively, with 5Fr single-pigtail, unflanged stents and 5-Fr straight, flanged stents producing similar results [108]. Furthermore, placement of 5 -Fr stents requires fewer guidewires and is easier than that of 3-Fr stents [109, 110]. It is believed that stents need to remain in place for a minimum of $12-24$ hours to provide benefit, since removal at the end of ERCP negates the protection from PEP [111] and early outward migration may also result in PEP [112]. Adverse events related to attempted prophylactic pancreatic stenting include PEP, stent-induced pancreatic ductal damage, and inward migration [113]. Removal of proximally migrated small-diameter stents can be technically challenging, if not impossible [114].

\section{ERCP techniques}

$\nabla$

\subsection{General considerations}

\subsubsection{Patient position}

\section{- Statement 2010:}

There is no evidence that the incidence of PEP is influenced by patient position during ERCP (Evidence level $2++$ ). Therefore, no recommendation is made regarding patient position.

\section{- Statement 2014:}

No changes.

\section{Background:}

Comparisons in RCTs of different patient positions during ERCP showed no significant difference in PEP incidence.

\section{New information since 2009:}

None.

\subsubsection{Cannulation attempts}

\section{- Statement 2010:}

Trauma resulting from repeated attempts at biliary cannulation has been proven to be a risk factor for the development of PEP (Evidence level $2++$ ). The number of cannulation attempts should be minimized (Recommendation grade $\mathrm{B}$ ).

\section{- Statement 2014:}

ESGE recommends keeping the number of cannulation attempts as low as possible (Recommendation grade B).

\section{Background:}

The risk of PEP is higher after multiple attempts at duct cannulation $[6,21,115,116]$. The rendezvous technique allows cannulation trauma to be minimized, and has been used in most studies that evaluated intraoperative endoscopic sphincterotomy.

\section{New information since 2009:}

A meta-analysis assessed 5 RCTs that compared preoperative vs. intraoperative endoscopic sphincterotomy [117]; PEP was less frequent with the latter approach while the incidence of other ERCP-related complications was similar with both techniques. A nationwide case - control study from Sweden confirmed that the rendezvous technique was associated with a reduction in the risk of PEP compared with standard cannulation techniques, from $3.6 \%$ to $2.2 \%$ (OR 0.5; 95\%CI $0.2-0.9 ; P=0.02$ ) [18]. 


\subsubsection{Contrast medium}

\section{- Statement 2010:}

Injection of contrast medium into the pancreatic duct is an independent predictor of PEP (Evidence level 1+). If pancreatic duct injection occurs incidentally or is required, the number of injections and volume of contrast medium injected into the pancreatic duct should be kept as low as possible (Recommendation grade B). Compared with traditional, high-osmolality contrast agents, low-osmolality contrast agents are costlier but are not associated with reduction in the rates of PEP (Evidence level 1-). The routine use of these agents for ERCP is not recommended (Recommendation grade $\mathrm{B}$ ).

\section{- Statement 2014:}

No changes.

\section{Background:}

In a large meta-analysis, pancreatic duct injection was found to be an independent predictor of PEP (RR 2.2; 95\%CI 1.60-3.01) [20]. In a retrospective study that included more than 14000 ERCPs, the extent of pancreatic duct injection (head-only vs. head and body vs. injection to the tail) was independently associated with PEP [118]. The hypothesis that low-osmolality contrast agents would be less harmful than high-osmolality contrast agents because of less important fluid shifts in the pancreas was invalidated in a meta-analysis of 13 RCTs that involved 3381 patients [119].

\section{New information since 2009:}

One article examined the role of low-osmolality contrast agents but it does not warrant any change in the Guideline [120].

\subsubsection{Carbon dioxide}

- Statement 2010:

Use of carbon dioxide (CO2) as a replacement for air for luminal insufflation during ERCP does not influence the incidence of PEP but decreases the incidence and severity of post-procedural abdominal pain (Evidence level 1+). Carbon dioxide is recommended for insufflation, and might be particularly useful for outpatient ERCPs, to reduce post-procedural abdominal pain and to avoid confusion with PEP (Recommendation grade B).

\section{- Statement 2014:}

No changes.

\section{Background:}

Because of its higher solubility in water compared with nitrogen and oxygen, the main components of air, carbon dioxide is cleared from the bowel following endoscopy much faster than air (through the bloodstream and respiration).

\section{New information since 2009:}

Three meta-analyses, which included between 5 and 7 RCTs (between 446 and 818 patients), compared carbon dioxide vs. air for gut distension during ERCP exclusively [121-123]. All these meta-analyses found that the use of carbon dioxide reduces post-ERCP abdominal pain without change in other complication rates or in procedure duration. A survey showed that the use of carbon dioxide during endoscopy is uncommon; this may be related to implementation costs and unawareness by endoscopists of the advantages of carbon dioxide [124].

\subsubsection{Cannulation techniques}

\section{- Statement 2010:}

For deep biliary cannulation, the wire-guided technique reduces the risk of PEP and increases the success rate of primary cannulation when compared with the standard contrast-assisted method
(Evidence level $1++$ ). The wire-guided technique is recommended for deep biliary cannulation (Recommendation grade A).

\section{- Statement 2014:}

No changes.

Background:

The wire-guided biliary cannulation technique entails passage of a guidewire inserted through a catheter (most often a hydrophilic guidewire inserted into a sphincterotome) for deeply cannulating the bile duct. Two meta-analyses published in 2009 showed that, in RCTs, the incidence of PEP was significantly lower with the wire-guided as compared with the standard contrast-assisted cannulation technique $[125,126]$.

\section{New information since 2009:}

Five comparative studies and a meta-analysis comparing the wire-guided vs. the standard contrast-assisted method for selective biliary cannulation were published between 2009 and 2013 [127-132]. Four studies [128-131], two of which were RCTs $[128,131]$, did not confirm the results of previous meta-analyses that showed a lower risk of PEP with the wire-guided method. In most studies, the wire-guided method shortened cannulation and fluoroscopy times. However, in a recent meta-analysis that extended the analysis to 12 RCTs (3450 patients), the wire-guided method significantly lowered the incidence of PEP compared with the contrast-assisted method (RR $0.51 ; 95 \% \mathrm{Cl}, 0.32-0.82$ ) [132]. In addition, the wire-guided cannulation technique was associated with greater primary cannulation success (RR 1.07; $95 \%$ CI $1.00-1.15$ ), fewer precut sphincterotomies (RR 0.75; 95\% CI 0.60-0.95), and no increase in other ERCP-related complications.

\subsubsection{Electrosurgical current \\ - Statement 2010:}

The incidence of post-sphincterotomy pancreatitis is not influenced by the type of electrosurgical current used (whether pure-cut or blended) (Evidence level 1+). Blended current is recommended for biliary sphincterotomy, particularly in patients at high risk of bleeding (Recommendation grade A).

\section{- Statement 2014:}

\section{No changes.}

Background:

As pure-cut current produces less edema than blended current [133], it was hypothesized that it might reduce the incidence of PEP after biliary sphincterotomy. A meta-analysis of four RCTs that included 804 patients found no significant difference in the incidence of PEP following the use of pure vs. blended current [134]. However, the incidence of bleeding was significantly higher when pure-cut current was used.

\section{New information since 2009:}

No new evidence has become available.

\subsection{Effect of difficult biliary cannulation}

\subsubsection{Definition}

\section{- Statement 2010:}

None.

\section{- Statement 2014:}

ESGE recommends that future studies define difficult biliary cannulation in an intact papilla as any of the following: cannulation attempts of duration $>5$ minutes, $>5$ attempts, or 2 pancreatic guidewire passages. 


\section{Background:}

Many different definitions of "difficult" biliary cannulation have been used, which make comparisons between studies impractical.

New information since 2009:

In an effort to standardize this definition, Halttunen et al. prospectively collected data on 907 biliary cannulations attempted by experienced endoscopists at 10 centers [115]. The authors found the incidence of PEP progressively increased with various factors perceived as causing difficulty in cannulation. Any of the following factors was associated with a PEP incidence of $>10 \%$ during wire-guided cannulation of a native papilla: cannulation attempts of duration $>5$ minutes, $>5$ attempts, or 2 pancreatic guidewire passages. The latter was also noted in another prospective study [116].

For difficult cannulation, commonly used options include persistent attempts at cannulation using standard methods, pancreatic guidewire placement (with biliary cannulation attempted either using a guidewire, the so-called "double guidewire" (DGW) technique, or using contrast medium injection), precut of various types, repeat attempts at ERCP 24-48 hours later, and patient referral to another endoscopist.

\subsubsection{Pancreatic guidewire-assisted technique - Statement 2010:}

Data about the usefulness and safety of pancreatic guide wire placement to facilitate biliary cannulation in difficult cases are conflicting. Prophylactic pancreatic stent placement decreases the incidence of PEP with this technique (Evidence level 2+). Pancreatic guide wire assistance may facilitate biliary cannulation mostly in the case of inadvertent but repeated cannulation of the pancreatic duct; if this method is used, a pancreatic stent should be placed for PEP prophylaxis (Recommendation grade B).

\section{- Statement 2014:}

In cases of difficult biliary cannulation, pancreatic guidewire (PGW) placement allows biliary cannulation in a proportion of cases similar to persistence in attempting cannulation with standard cannulation techniques (or precut if it is used as a backup technique), but the risk of PEP is likely higher. In such circumstances, PEP is effectively prevented by prophylactic pancreatic stenting (Evidence level 1-). ESGE suggests restricting the use of a PGW as a backup technique to cases with repeated inadvertent cannulation of the pancreatic duct; if this method is used, deep biliary cannulation should be attempted using a guidewire rather than the contrast-assisted method and a prophylactic pancreatic stent should be placed (Recommendation grade B).

\section{Background:}

In the PGW-assisted technique, a guidewire is inserted in the main pancreatic duct to facilitate deep biliary cannulation by straightening the papillary anatomy and to prevent repeated cannulation of the pancreatic duct $[135,136]$. In two RCTs, compared with persistence in applying the standard cannulation technique, the PGW technique yielded overall similarly low success rates for biliary cannulation (means, $57 \%$ vs. 56\%, respectively) and a nonsignificantly higher incidence of PEP (means, $14 \%$ vs. $6 \%$, respectively) $[137,138]$. Discordances between these RCTs in terms of cannulation success and of PEP incidence may be related to differences in the inclusion criteria (i.e., difficult biliary cannulation alone or combined with repeated unintended pancreatic cannulation) and in the use of prophylactic pancreatic stenting.

\section{New information since 2009:}

Seven new studies are summarized in $\bullet$ Table 3 [139-145]. In two RCTs that compared the PGW vs. the precut techniques $[142,143]$, success rates of biliary cannulation were similar but, in one of the RCTs [143], the PGW technique was plagued by a higher incidence of PEP ( $38 \%$ vs. $11 \%$, respectively; $P=0.01$ ). Prophylactic pancreatic stenting was not used in any of the RCTs mentioned above. Another RCT showed that prophylactic pancreatic stenting significantly decreased the incidence of PEP after the PGW technique had been used [146]. In a retrospective study that included 146 patients, prophylactic pancreatic stenting was always attempted after the PGW technique had been used, and failed prophylactic pancreatic stenting was the only independent predictor of PEP [144]. In another retrospective study that involved 142 patients, the incidence of PEP decreased after the authors changed their cannulation technique following PGW placement, from contrast-assisted to guidewire-assisted biliary cannulation [147].

\subsubsection{Precut biliary sphincterotomy \\ - Statement 2010:}

Various techniques of precut biliary sphincterotomy have been described; the fistulotomy technique may present a lower incidence of PEP than standard needle-knife sphincterotomy but further RCTs are required to determine which technique is safer and more effective, based upon the papillary anatomy. There is no evidence that the success and complication rates of biliary precut are affected by the level of endoscopist experience in this technique but published data only report on the experience of one endoscopist (Evidence level 2 - ). Prolonged cannulation attempts using standard techniques may impart a risk for PEP greater than the precut sphincterotomy itself (Evidence level 2+). Precut sphincterotomy should be performed by endoscopists with expertise in standard cannulation techniques (Recommendation grade $\mathrm{D}$ ). The decision to perform precut biliary sphincterotomy, the timing, and the technique, are based on anatomic findings, endoscopist preference, and procedural indication (Recommendation grade $\mathrm{C}$ ).

\section{- Statement 2014:}

In cases of difficult biliary cannulation, early precut is associated with a lower PEP incidence than persistent attempts using the standard approach but the overall success and complication rates are similar with both approaches. Needle-knife fistulotomy seems to be associated with fewer complications, including PEP, compared with other precut techniques.

ESGE suggests that needle-knife fistulotomy should be the preferred precut technique in patients with a bile duct dilated down to the papilla. Conventional precut and transpancreatic sphincterotomy present similar success and complication rates; if conventional precut is elected and pancreatic cannulation is easily obtained, ESGE suggests attempting to place a small-diameter (3-Fr or 5-Fr) pancreatic stent to guide the cut and leaving the pancreatic stent in place at the end of ERCP for a minimum of $12-24$ hours (Recommendation grade B).

\section{Background:}

Precut biliary sphincterotomy can be done by different techniques: needle-knife precut starting at the orifice of the papilla (conventional precut), needle-knife above the orifice (fistulotomy), transpancreatic sphincterotomy (septotomy) and needleknife over a pancreatic stent. Compared with prolonged attempts at biliary cannulation using standard techniques, the use of pre- 
Table 3 New studies evaluating pancreatic guidewire (PGW) placement for biliary cannulation in the case of difficult biliary cannulation.

\begin{tabular}{|c|c|c|c|c|c|c|}
\hline $\begin{array}{l}\text { First author, } \\
\text { year }\end{array}$ & $\begin{array}{l}\text { Design } \\
\text { Patients, } \mathbf{n}\end{array}$ & $\begin{array}{l}\text { Additional } \\
\text { inclusion criteria }\end{array}$ & $\begin{array}{l}\text { Pancreatic } \\
\text { stenting }\end{array}$ & $\begin{array}{l}\text { Successful biliary } \\
\text { cannulation rate }\end{array}$ & PEP rate & Note \\
\hline $\begin{array}{l}\text { Xinopoulos, } \\
2011 \text { [139] }\end{array}$ & $\begin{array}{l}\text { Retrospective } \\
112\end{array}$ & $\begin{array}{l}\text { Repeated uninten- } \\
\text { tional pancreatic } \\
\text { duct cannulation }\end{array}$ & No & $\begin{array}{l}44 \% \text { (vs. } 81 \% \text { with } \\
\text { precut in patients who } \\
\text { had no repeated un- } \\
\text { intentional pancreatic } \\
\text { duct cannulation) }\end{array}$ & $\begin{array}{l}6.1 \% \text { (similar to } \\
\text { group with easy } \\
\text { biliary cannula- } \\
\text { tion [5.3\%] and to } \\
\text { group with precut } \\
\text { in place of PGW } \\
\text { [7.5\%]) }\end{array}$ & Comparative study \\
\hline $\begin{array}{l}\text { Grönroos, } \\
2011[140]\end{array}$ & $\begin{array}{l}\text { Prospective } \\
50\end{array}$ & $\begin{array}{l}\text { Repeated uninten- } \\
\text { tional pancreatic } \\
\text { duct cannulation }\end{array}$ & No & $66 \%$ & $2 \%$ & $\begin{array}{l}\text { Authors advocate } \\
\text { to shift to other } \\
\text { technique if DGW is } \\
\text { cumbersome }\end{array}$ \\
\hline $\begin{array}{l}\text { Belverde, } \\
2012 \text { [141] }\end{array}$ & $\begin{array}{l}\text { Retrospective } \\
121\end{array}$ & $\begin{array}{l}\text { Selective pancreat- } \\
\text { ic duct cannulation } \\
\text { achieved }\end{array}$ & No & $97 \%$ & $2.6 \%$ & \\
\hline $\begin{array}{l}\text { Angsuwatcharakon, } \\
2012 \text { [142] }\end{array}$ & $\begin{array}{l}\text { RCT } \\
44\end{array}$ & No & No & $\begin{array}{l}\text { PGW vs. precut: } \\
74 \% \text { vs. } 81 \% \text { (n.s.) }\end{array}$ & $\begin{array}{l}\text { PGW vs. precut: } \\
17.4 \% \text { vs. } 9.5 \%\end{array}$ & $\begin{array}{l}\text { Shorter cannula- } \\
\text { tion time with the } \\
\text { PGW vs. precut } \\
\text { technique } \\
(172 \text { s vs. } 394 \text { s } \\
(P<0.001)\end{array}$ \\
\hline $\begin{array}{l}\text { Yoo, } \\
2013 \text { [143] }\end{array}$ & $\begin{array}{l}\text { RCT } \\
71\end{array}$ & $\begin{array}{l}\text { Selective pancrea- } \\
\text { tic duct cannula- } \\
\text { tion achieved }\end{array}$ & No & $\begin{array}{l}\text { DGW vs. precut: } \\
91.2 \% \text { vs. } 91.9 \% \text { (n.s.) }\end{array}$ & $\begin{array}{l}\text { DGW vs. precut: } \\
38 \% \text { vs. } 11 \% \\
(P=0.01)\end{array}$ & \\
\hline $\begin{array}{l}\text { Ito, } \\
2013[144]^{*}\end{array}$ & $\begin{array}{l}\text { Retrospective } \\
146\end{array}$ & n.a. & Attempted in all & $\begin{array}{l}\text { PGW: } 70 \% \text {; } \\
\text { if failure with PGW, } \\
\text { DGW was successful in } \\
72 \%\end{array}$ & $\begin{array}{l}\text { PGW, } 8 \% \\
\text { DGW, } 4 \%\end{array}$ & $\begin{array}{l}\text { Independent } \\
\text { predictor of PEP: } \\
\text { failed pancreatic } \\
\text { stenting (OR } 8.3 \text {; } \\
95 \% \mathrm{Cl} 2.3-30)\end{array}$ \\
\hline $\begin{array}{l}\text { Tanaka, } \\
2013[145]^{1}\end{array}$ & $\begin{array}{l}\text { Retrospective } \\
79\end{array}$ & $\begin{array}{l}\text { Opacification of } \\
\text { the pancreatic duct }\end{array}$ & $40 / 79$ & $\begin{array}{l}82 \% \text { (PGW) vs. } 83 \% \\
\text { (DGW) }\end{array}$ & $\begin{array}{l}11 \% \text { (PGW) vs. } 7 \% \\
\text { (DGW) }\end{array}$ & \\
\hline
\end{tabular}

PEP, post-endoscopic retrograde cholangiopancreatography (post-ERCP) pancreatitis; PGW, pancreatic guidewire; DGW, double guidewire; RCT, randomized controlled trial; n.s., not significant; n.a., not available; OR, odds ratio; Cl, confidence interval

${ }^{1}$ Biliary cannulation attempted by searching the bile duct through contrast medium injection with a guidewire in the main pancreatic duct (PGW technique), as opposed to searching through manipulation of a guidewire inserted in a catheter (DGW technique).

cut sphincterotomy has long been thought to increase the success of biliary cannulation and the incidence of PEP $[6,20]$.

\section{New information since 2009:}

Two meta-analyses investigated the issue of timing of the precut procedure in 6 RCTs $[148,149]$. Aside from the definition of early precut, differences between studies included the technique of precut and the randomization ratio (from 1:1 to 1:3). Endoscopists experienced in precut techniques performed all procedures. The overall incidence of PEP was lower in patients allocated to early precut than to persistence in the use of standard techniques ( $2.5 \%$ vs. $5.3 \%$; OR $0.47 ; 95 \% \mathrm{CI} 0.24-0.91$ ) but the overall cannulation and complication rates were similar in patients allocated to early precut or to persistence in the use of standard cannulation techniques.

In a retrospective study comparing different precut techniques, the risk of PEP was significantly lower after fistulotomy (2.6\%) compared with conventional precut $(20.9 \%)$ and pancreatic septotomy (22.4\%); the overall complication rate was also significantly lower after fistulotomy vs. other precut techniques [150]. In another retrospective study of needle-knife fistulotomy performed in 204 patients, complications (mostly PEP) progressively increased with decreasing common bile duct (CBD) diameter, up to $14 \%$ in patients with a CBD diameter < $4 \mathrm{~mm}$ [151]. Two retrospective studies compared transpancreatic septotomy and needle-knife precut (with pancreatic stenting or not) for biliary ac- cess $[152,153]$; they found no significant differences in terms of PEP, overall complication and overall success rates.

Needle-knife precut assisted by pancreatic stenting has been proposed for reducing PEP. One RCT found that, compared with stent removal at the end of the procedure, leaving the stent for 7-10 days reduces the incidence and severity of PEP $(P<0.05$ for both comparisons) [111].

\subsection{Specific therapeutic techniques}

\subsubsection{Balloon dilation as a substitute for endoscopic} sphincterotomy

\section{- Statement 2010:}

Compared with endoscopic sphincterotomy, endoscopic papillary balloon dilation (EPBD) using small-caliber balloons $(\leq 10$ $\mathrm{mm}$ ) is associated with a significantly higher incidence of PEP and significantly less bleeding (Evidence level $1++$ ). EPBD is not recommended as an alternative to sphincterotomy in routine ERCP but may be useful in patients with coagulopathy and altered anatomy (e.g. Billroth II) (Recommendation grade A). If balloon dilation is performed in young patients, the placement of a prophylactic pancreatic stent should be strongly considered (Evidence level 4; Recommendation grade D).

\section{- Statement 2014:}

Compared with endoscopic sphincterotomy, endoscopic papillary balloon dilation (EPBD) using small-caliber balloons $(\leq 10$ $\mathrm{mm}$ ) is associated with more PEP, less bleeding, and fewer late 
stone recurrences; the risk of PEP is inversely associated with the duration of EPBD (Evidence level 1++). ESGE does not recommend endoscopic papillary balloon dilation as an alternative to sphincterotomy in routine ERCP, but it may be advantageous in selected patients; if this technique is used, the duration of dilation should be longer than 1 minute (Recommendation grade A). Background:

The use of EPBD may be advantageous compared with endoscopic sphincterotomy, by decreasing clinically significant bleeding in patients with coagulopathy, for preserving sphincter of Oddi function in younger patients [154], and in patients with altered anatomy (Billroth II) where sphincterotomy is technically difficult. In two meta-analyses, the use of EPBD resulted in a lower success rate than endoscopic sphincterotomy for the initial removal of biliary stones, with a significantly higher incidence of PEP and significantly lower incidence of bleeding $[155,156]$.

New information since 2009:

A meta-analysis of 10 high quality RCTs (1451 patients) that compared EPBD vs. endoscopic sphincterotomy for biliary stone extraction found similar success rates of biliary stone extraction with both methods but did not bring new findings with regard to complications [157]; indeed it included fewer RCTs than the previously published Cochrane meta-analysis [156].

A meta-analysis that included 12 RCTs (1649 patients) indicated that duration of EPBD is inversely associated with the incidence of PEP: short ( $\leq 1$ minute) EPBD was associated with a higher risk of PEP (OR 3.87; 95\%CI 1.08-13.84) compared with endoscopic sphincterotomy (4 RCTs), but long EPBD inflation time (>1 minute) was not (OR 1.14; 95\%CI 0.56-2.35) (6 RCTs) [158]. A lower risk of PEP after long EPBD was also reported in the single RCT that compared long (5-minute) vs. short (1-minute) EPBD (RR 0.32; 95\%CI 0.11-0.93) [159]. The authors suggested that the increased risk of PEP after short EPBD might be related to inadequate balloon expansion resulting in a worsened compression of the pancreatic duct.

A meta-analysis that included 3 RCTs (496 patients) with a follow-up longer than 1 year showed that stone recurrence was less frequent after EPBD vs. endoscopic sphincterotomy (OR $0.48 ; 95 \%$ CI $0.26-0.90$ ) [160]. Another RCT that was not included in this meta-analysis and included 474 patients also reported that, in patients with biliary stones $\leq 8 \mathrm{~mm}$, overall late complications and stone recurrence were less frequent after EPBD than after endoscopic sphincterotomy ( $5.3 \%$ vs. $17.3 \%, P=0.009 ; 4.4 \%$ vs. $12.7 \% ; P=0.048$, respectively) (mean follow-up, 55 months); the difference was not significant for patients with stones $>8$ $\mathrm{mm}$ [161]. A retrospective cohort study with a median followup of 92 months also showed a lower incidence of common bile duct stone recurrence after EPBD vs. endoscopic sphincterotomy [162].

\subsubsection{Large-balloon dilation for extraction of difficult biliary stones}

\section{- Statement 2010:}

Potential advantages of performing large-balloon dilation in addition to endoscopic sphincterotomy for extraction of difficult biliary stones remain unclear (Evidence level 3). Endoscopic sphincterotomy plus large-balloon dilation does not seem to increase the risk of PEP and can avoid the need for mechanical lithotripsy in selected patients, but not enough data are available to recommend routine use over biliary sphincterotomy alone in conjunction to lithotripsy techniques (Recommendation grade D).

\section{- Statement 2014:}

For the extraction of difficult biliary stones, endoscopic sphincterotomy plus large-balloon dilation presents a risk of PEP similar to that of endoscopic sphincterotomy alone; it presents a lower bleeding risk and, possibly, lower overall morbidity and requires less use of mechanical lithotripsy. ESGE suggests performing endoscopic sphincterotomy plus large-balloon dilation in place of endoscopic sphincterotomy alone for the extraction of selected difficult biliary stones (Recommendation grade B).

\section{Background:}

In patients with a tapered distal bile duct or large biliary stones, endoscopic sphincterotomy followed by biliary dilation using a large-diameter $(12-20 \mathrm{~mm})$ balloon has been proposed to facilitate stone extraction [163]. This technique has been associated with high success rates for stone extraction without the need for mechanical lithotripsy and with acceptable complication rates in case series [164-167]; the single RCT that had compared this method with endoscopic sphincterotomy at the time of publication of the first Guideline had found no differences in rates of successful stone clearance, need for mechanical lithotripsy, and complications [168].

\section{New information since 2009:}

A meta-analysis of 7 RCTs that included 790 patients found that, compared with endoscopic sphincterotomy alone, endoscopic sphincterotomy followed by large balloon dilation was associated with similar PEP rates but significantly fewer overall complications and significantly less bleeding [169]. However in this meta-analysis, studies which, according to their authors, were retrospective, were considered to be RCTs [170]. Two other meta-analyses that included 3 RCTs and 4-6 retrospective studies (including between 90 and 1295 patients) found similar incidences of PEP but significantly lower bleeding risk with endoscopic sphincterotomy plus large balloon dilation vs. endoscopic sphincterotomy [171,172]. Additional differences in favor of endoscopic sphincterotomy plus large balloon dilation were mostly attributable to the results of retrospective studies; they included a lower use of mechanical lithotripsy and a lower overall complication rate $[171,172]$.

\subsubsection{Sphincter of Oddi manometry \\ - Statement 2010:}

In patients undergoing pancreatic sphincter of Oddi manometry, use of the standard perfusion catheter without an aspiration port has been shown to increase the risk of PEP compared with modified water perfusion catheters (Evidence level $2++$ ). Pancreatic sphincter of Oddi manometry should be done using a modified triple-lumen perfusion catheter with simultaneous aspiration or a microtransducer catheter (non-water-perfused) (Recommendation grade $\mathrm{B})$.

\section{- Statement 2014:}

ESGE recommends that all patients undergoing ERCP for known or suspected sphincter of Oddi dysfunction (SOD) receive rectal NSAIDs combined with pancreatic stenting. Pancreatic sphincter of Oddi manometry should be done using a modified triple-lumen perfusion catheter with simultaneous aspiration or a microtransducer catheter (non-water-perfused) (Recommendation grade B).

\section{Background:}

It is well documented that patients undergoing ERCP for known or suspected SOD are at high risk of PEP, regardless of whether sphincter of Oddi manometry (SOM) is performed [173]. Biliary SOM does not appear to increase the risk of PEP [173]; pancreatic 
SOM is associated with an increased risk of PEP depending on the technique used [174]. When water-perfused catheters are used to measure pancreatic sphincter pressure, continuous aspiration of fluid from the main pancreatic duct through one of the three manometry ports prevents overfilling of the duct [174], a known risk factor for PEP. A specialized aspiration manometry catheter is available for this purpose, though one port of a standard triple lumen catheter can be used for aspiration [174]. The use of solidstate manometry catheters decreases the risk of PEP as there is no perfusion or filling of the pancreatic duct [175].

The results of SOM should not influence the decision of whether to institute measures for prevention of PEP. As mentioned, all patients with known or suspected SOD are at high risk for PEP and should receive PEP prophylaxis [175]. Indeed one study showed that pancreatic stent placement reduced PEP in patients with an intact papilla undergoing SOM and when the manometry results were normal [176].

\section{New information since 2009:}

Recent data suggest that rectal NSAIDs are at least as effective as pancreatic stents in patients with SOD $[34,44,107]$. However, the most evidence-based approach for preventing PEP in high risk cases remains the combination of rectal NSAIDs and prophylactic pancreatic stenting. In the RCT mentioned above, patients who received rectal indomethacin and a pancreatic stent $(n=247)$ had a PEP rate of $9.7 \%$ compared with $16.1 \%$ in those who received a stent alone $(n=249)(P=0.04)$ [34]. To date, there are no clinical trial data examining whether rectal NSAIDs are effective when administered instead of prophylactic pancreatic stenting. The data apply mainly to the initial SOM or in patients with SOD and intact papillae. One exception to routine PEP prophylaxis might be in patients with SOD who have had dual sphincterotomy and continued pain who undergo repeat ERCP with re-evaluation. If both sphincters are found to be patent and/or only the biliary sphincter is studied, one might consider not placing a pancreatic stent. However, the risk of administration of one dose of rectal NSAIDS is so small that its use outweighs the risk of avoiding them.

\section{Selection of measures for PEP prophylaxis}

\section{$\nabla$}

\section{- Statement 2010:}

For low-risk ERCPs, periprocedural rectal administration of nonsteroidal anti-inflammatory drugs (NSAIDs) is recommended. For high risk ERCPs, prophylactic pancreatic stent placement should be strongly considered (Evidence level 1+; Recommendation grade $\mathrm{A}$ ).

\section{- Statement 2014:}

ESGE recommends routine rectal administration of $100 \mathrm{mg}$ of diclofenac or indomethacin immediately before or after ERCP in all patients without contraindication. In addition to this, in cases at high risk for PEP, the placement of a 5-Fr prophylactic pancreatic stent should be strongly considered. Sublingually administered GTN or $250 \mu$ g somatostatin given in bolus injection might be considered as an option in high risk cases if NSAIDs are contraindicated and if prophylactic pancreatic stenting is not possible or successful (Recommendation grade A).

The following conditions are considered to represent high risk for PEP: endoscopic ampullectomy, known or suspected SOD, pancreatic sphincterotomy, precut biliary sphincterotomy, pancreatic guidewire-assisted biliary cannulation, endoscopic balloon sphincteroplasty, and presence of more than three of the risk fac- tors listed in Table 1 (definite or likely). Procedures and patient conditions that do not fulfill these criteria are considered to represent low risk for PEP.

Competing interests: None of the authors reports financial competing interests.

\section{Institutions \\ ${ }^{1}$ Gedyt Endoscopy Center, Buenos Aires, Argentina \\ ${ }^{2}$ Division of Gastroenterology, Casa Sollievo Sofferemza Hospital, IRCCS, \\ San Giovanni Rotondo, Italy \\ ${ }^{3}$ Division of Gastroenterology, Medical University of South Carolina, Charles- ton, South Carolina, USA \\ ${ }^{4}$ Division of Gastroenterology and Gastrointestinal Endoscopy, Vita-Salute San Raffaele University, Scientific Institute San Raffaele, Milan, Italy \\ ${ }^{5}$ Department of Gastroenterology, HELIOS Albert-Schweitzer Klinik, Göttingen University Teaching Hospital, Northeim, Germany \\ ${ }^{6}$ Departments of Gastroenterology and Hepato-Pancreatology, Erasme \\ University Hospital, Université Libre de Bruxelles, Brussels, Belgium \\ ${ }^{7}$ Department of Gastroenterology, Silesian Academy of Medicine, Medyków, Katowice, Poland \\ ${ }^{8}$ Division of Gastroenterology and Hepatology, University of North Carolina, Chapel Hill, North Carolina, USA \\ ${ }^{9}$ Digestive Endoscopy Unit, Catholic University, Rome, Italy \\ ${ }^{10}$ Department of Gastroenterology and Hepatology, Elisabethinen Hospital, Linz, Austria}

\section{References}

1 Dumonceau JM, Andriulli A, Devière J et al. European Society of Gastrointestinal Endoscopy (ESGE) Guideline: prophylaxis of post-ERCP pancreatitis. Endoscopy 2010; 42: 503-515

2 Dumonceau J-M, Rigaux J, Kahaleh $M$ et al. Prophylaxis of post-ERCP pancreatitis: a practice survey. Gastrointest Endosc 2010; 71: 934939 (e931-e932)

3 Kapral C, Mühlberger A, Wewalka F et al. Quality assessment of endoscopic retrograde cholangiopancreatography: results of a running nationwide Austrian benchmarking project after 5 years of implementation. Eur J Gastroenterol Hepatol 2012; 24: 1447-1454

4 Hanna MS, Portal AJ, Dhanda AD et al. UK wide survey on the prevention of post-ERCP pancreatitis. Frontline Gastroenterol 2014; 5: 103 110

5 Cotton PB, Lehman G, Vennes J et al. Endoscopic sphincterotomy complications and their management: an attempt at consensus. Gastrointest Endosc 1991; 37: 383-393

6 Freeman ML, Nelson DB, Sherman $S$ et al. Complications of endoscopic biliary sphincterotomy. N Engl J Med 1996; 335: 909-918

7 Banks PA, Bollen TL, Dervenis C et al. Classification of acute pancreatitis-2012: revision of the Atlanta classification and definitions by international consensus. Gut 2013; 62: $102-111$

8 Artifon EL, Chu A, Freeman M et al. A comparison of the consensus and clinical definitions of pancreatitis with a proposal to redefine postendoscopic retrograde cholangiopancreatography pancreatitis. Pancreas 2010; 39: 530-535

9 Dellinger EP, Forsmark CE, Layer $P$ et al. Determinant-based classification of acute pancreatitis severity: an international multidisciplinary consultation. Ann Surg 2012; 256: 875-880

10 Andriulli A, Loperfido $S$, Napolitano $G$ et al. Incidence rates of post-ERCP complications: a systematic survey of prospective studies. Am J Gastroenterol 2007; 102: $1781-1788$

11 Sutton VR, Hong MK, Thomas PR. Using the 4-hour post-ERCP amylase level to predict post-ERCP pancreatitis. JOP 2011; 12: $372-376$

12 Williams EJ, Taylor S, Fairclough $P$ et al. Are we meeting the standards set for endoscopy? Results of a large-scale prospective survey of endoscopic retrograde cholangio-pancreatograph practice Gut 2007; 56: $821-829$

13 Varadarajulu S, Kilgore ML, Wilcox CM et al. Relationship among hospital ERCP volume, length of stay, and technical outcomes. Gastrointest Endosc 2006; 64: 338 - 347

14 Allison MC, Ramanaden DN, Fouweather MG et al. Provision of ERCP services and training in the United Kingdom. Endoscopy 2000; 32: $693-$ 699

15 Hilsden RJ, Romagnuolo J, May GR. Patterns of use of endoscopic retrograde cholangiopancreatography in a Canadian province. Can J Gastroenterol 2004; 18: 619-624 
16 Loperfido S, Angelini G, Benedetti $G$ et al. Major early complications from diagnostic and therapeutic ERCP: a prospective multicenter study. Gastrointest Endosc 1998; 48: 1 - 10

17 Williams EJ, Taylor S, Fairclough P et al. Risk factors for complication following ERCP; results of a large-scale, prospective multicenter study. Endoscopy 2007; 39: 793-801

18 Swahn F, Nilsson M, Arnelo $U$ et al. Rendezvous cannulation technique reduces post-ERCP pancreatitis: a prospective nationwide study of 12,718 ERCP procedures. Am J Gastroenterol 2013; 108: 552 - 559

19 Testoni PA, Mariani A, Giussani A et al. Risk factors for post-ERCP pancreatitis in high- and low-volume centers and among expert and nonexpert operators: a prospective multicenter study. Am J Gastroenterol 2010; 105: $1753-1761$

20 Masci E, Mariani A, Curioni S et al. Risk factors for pancreatitis following endoscopic retrograde cholangiopancreatography: a meta-analysis. Endoscopy 2003; 35: 830-834

21 Freeman ML, DiSario JA, Nelson DB et al. Risk factors for post-ERCP pancreatitis: a prospective, multicenter study. Gastrointest Endosc 2001; 54: $425-434$

22 Masci E, Toti G, Mariani A et al. Complications of diagnostic and therapeutic ERCP: a prospective multicenter study. Am J Gastroenterol 2001; 96: 417-423

23 Harewood GC, Pochron NL, Gostout CJ. Prospective, randomized, controlled trial of prophylactic pancreatic stent placement for endoscopic snare excision of the duodenal ampulla. Gastrointest Endosc 2005; 62: $367-370$

24 Norton ID, Gostout CJ, Baron TH et al. Safety and outcome of endoscopic snare excision of the major duodenal papilla. Gastrointest Endosc 2002; 56: 239-243

25 Bailey AA, Bourke MJ, Kaffes AJ et al. Needle-knife sphincterotomy: factors predicting its use and the relationship with post-ERCP pancreatitis (with video). Gastrointest Endosc 2010; 71: 266-271

26 Cotton P, Garrow D, Gallagher J et al. Risk factors for complications after ERCP: a multivariate analysis of 11,497 procedures over 12 years. Gastrointest Endosc 2009; 70: 80-88

27 Wilcox CM, Phadnis M, Varadarajulu S. Biliary stent placement is associated with post-ERCP pancreatitis. Gastrointest Endosc 2010; 72: $546-550$

28 Swan MP, Alexander S, Moss A et al. Needle knife sphincterotomy does not increase the risk of pancreatitis in patients with difficult biliary cannulation. Clin Gastroenterol Hepatol 2013; 11: 430 - 436 .e431

29 Meister T, Heinzow H, Heinecke A et al. Post-ERCP pancreatitis in 2364 ERCP procedures: is intraductal ultrasonography another risk factor? Endoscopy 2011; 43: 331 - 336

30 Gottlieb K, Sherman S, Pezzi J et al. Early recognition of post-ERCP pancreatitis by clinical assessment and serum pancreatic enzymes. Am J Gastroenterol 1996; 91: 1553-1557

31 Dai HF, Wang XW, Zhao K. Role of nonsteroidal anti-inflammatory drugs in the prevention of post-ERCP pancreatitis: a meta-analysis. Hepatobiliary Pancreat Dis Int 2009; 8: 11-16

32 Elmunzer B, Waljee A, Elta $G$ et al. A meta-analysis of rectal NSAIDs in the prevention of post-ERCP pancreatitis. Gut 2008; 57: 1262

33 Zheng $M-H$, Xia $H$, Chen $Y$-P. Rectal administration of NSAIDs in the prevention of post-ERCP pancreatitis: a complementary meta-analysis. Gut 2008; 57: 1632

34 Elmunzer BJ, Scheiman JM, Lehman GA et al. A randomized trial of rectal indomethacin to prevent post-ERCP pancreatitis. N Engl J Med 2012; 366: $1414-1422$

35 Dobronte Z, Toldy E, Mark $L$ et al. [Effects of rectal indomethacin in the prevention of post-ERCP acute pancreatitis]. Orv Hetil 2012; 153: 990-996

36 Otsuka T, Kawazoe S, Nakashita S et al. Low-dose rectal diclofenac for prevention of post-endoscopic retrograde cholangiopancreatography pancreatitis: a randomized controlled trial. J Gastroenterol 2012; 47: $912-917$

37 Senol A, Saritas U, Demirkan H. Efficacy of intramuscular diclofenac and fluid replacement in prevention of post-ERCP pancreatitis. World J Gastroenterol 2009; 15: 3999-4004

38 Bhatia V, Ahuja V, Acharya SK et al. A randomized controlled trial of valdecoxib and glyceryl trinitrate for the prevention of post-ERCP pancreatitis. J Clin Gastroenterol 2011; 45: 170-176

39 Ding $X$, Chen $M$, Huang $S$ et al. Nonsteroidal anti-inflammatory drugs for prevention of post-ERCP pancreatitis: a meta-analysis. Gastrointest Endosc 2012; 76: $1152-1159$
40 Yaghoobi M, Rolland S, Waschke KA et al. Meta-analysis: rectal indomethacin for the prevention of post-ERCP pancreatitis. Aliment Pharmacol Ther 2013; 38: 995 - 1001

41 Sun HL, Han B, Zhai HP et al. Rectal NSAIDs for the prevention of postERCP pancreatitis: A meta-analysis of randomized controlled trials. Surgeon 2014; 12: $141-147$

42 Yuhara H, Ogawa M, Kawaguchi Y et al. Pharmacologic prophylaxis of post-endoscopic retrograde cholangiopancreatography pancreatitis: protease inhibitors and NSAIDs in a meta-analysis. J Gastroenterol 2014; 49: $388-399$

43 Sethi S, Sethi N, Wadhwa $V$ et al. A meta-analysis on the role of rectal diclofenac and indomethacin in the prevention of post-endoscopic retrograde cholangiopancreatography pancreatitis. Pancreas 2014; 43: $190-197$

44 Elmunzer BJ, Higgins PD, Saini SD et al. Does rectal indomethacin eliminate the need for prophylactic pancreatic stent placement in patients undergoing high-risk ERCP? Post hoc efficacy and cost-benefit analyses using prospective clinical trial data Am J Gastroenterol 2013; 108: $410-415$

45 Zhang Y, Chen $Q B$, Gao ZY et al. Meta-analysis: octreotide prevents post-ERCP pancreatitis, but only at sufficient doses. Aliment Pharmacol Ther 2009; 29: 1155-1164

46 Omata F, Deshpande G, Tokuda Y et al. Meta-analysis: somatostatin or its long-acting analogue, octreotide, for prophylaxis against postERCP pancreatitis. J Gastroenterol 2010; 45: 885-895

47 Katsinelos P, Fasoulas K, Paroutoglou G et al. Combination of diclofenac plus somatostatin in the prevention of post-ERCP pancreatitis: a randomized, double-blind, placebo-controlled trial. Endoscopy 2012; 44: $53-59$

48 Wang ZK, Yang YS, Cai FC et al. Is prophylactic somatostatin effective to prevent post-endoscopic retrograde cholangiopancreatography pancreatitis or hyperamylasemia? A randomized, placebo-controlled pilot trial Chin Med J (Engl) 2013; 126: 2403-2408

49 Andriulli A, Clemente R, Solmi $L$ et al. Gabexate or somatostatin administration before ERCP in patients at high risk for post-ERCP pancreatitis: a multicenter, placebo-controlled, randomized clinical trial. Gastrointest Endosc 2002; 56: 488 - 495

50 Andriulli A, Solmi L, Loperfido $S$ et al. Prophylaxis of ERCP-related pancreatitis: a randomized, controlled trial of somatostatin and gabexate mesylate. Clin Gastroenterol Hepatol 2004; 2: 713-718

51 Benvenutti S, Zancanella L, Piazzi L et al. Prevention of post-ERCP pancreatitis with somatostatin versus gabexate mesylate: A randomized placebo controlled multicenter study. Dig Liv Dis 2006; 38: S15

52 Cavallini G, Tittobello A, Frulloni L et al. Gabexate for the prevention of pancreatic damage related to endoscopic retrograde cholangiopancreatography. Gabexate in digestive endoscopy - Italian Group. N Engl J Med 1996; 335: 919-923

53 Manes G, Ardizzone S, Lombardi G et al. Efficacy of postprocedure administration of gabexate mesylate in the prevention of post-ERCP pancreatitis: a randomized, controlled, multicenter study. Gastrointest Endosc 2007; 65: 982-987

54 Xiong GS, Wu SM, Zhang XW et al. Clinical trial of gabexate in the prophylaxis of post-endoscopic retrograde cholangiopancreatography pancreatitis. Braz J Med Biol Res 2006; 39: 85-90

55 Fujishiro $H$, Adachi $K$, Imaoka $T$ et al. Ulinastatin shows preventive effect on post-endoscopic retrograde cholangiopancreatography pancreatitis in a multicenter prospective randomized study. J Gastroenterol Hepatol 2006; 21: 1065-1069

56 Yoo JW, Ryu JK, Lee SH et al. Preventive effects of ulinastatin on postendoscopic retrograde cholangiopancreatography pancreatitis in high-risk patients: a prospective, randomized, placebo-controlled trial. Pancreas 2008; 37: 366-370

57 Tsujino T, Komatsu Y, Isayama $H$ et al. Ulinastatin for pancreatitis after endoscopic retrograde cholangiopancreatography: a randomized, controlled trial. Clin Gastroenterol Hepatol 2005; 3: 376-383

58 Ueki T, Otani K, Kawamoto Ket al. Comparison between ulinastatin and gabexate mesylate for the prevention of post-endoscopic retrograde cholangiopancreatography pancreatitis: a prospective, randomized trial. J Gastroenterol 2007; 42: 161 -167

59 Chen S, Shi H, Zou X et al. Role of ulinastatin in preventing post-endoscopic retrograde cholangiopancreatography pancreatitis: the Emperor's New Clothes or Aladdin's Magic Lamp? Pancreas 2010; 39: 1231 1237 
60 Seta T, Noguchi Y. Protease inhibitors for preventing complications associated with ERCP: an updated meta-analysis. Gastrointest Endosc 2011; 73: 700 - 706 (e1-e2)

61 Zhang ZF, Yang N, Zhao G et al. Preventive effect of ulinastatin and gabexate mesylate on post-endoscopic retrograde cholangiopancreatography pancreatitis. Chin Med J (Engl) 2010; 123: 2600-2606

62 Choi CW, Kang DH, Kim GH et al. Nafamostat mesylate in the prevention of post-ERCP pancreatitis and risk factors for post-ERCP pancreatitis. Gastrointest Endosc 2009; 69: e11 - e18

63 Park KT, Kang DH, Choi CW et al. Is high-dose nafamostat mesilate effective for the prevention of post-ERCP pancreatitis, especially in highrisk patients? Pancreas 2011; 40: 1215-1219

64 Yoo KS, Huh KR, Kim YJ et al. Nafamostat mesilate for prevention of post-endoscopic retrograde cholangiopancreatography pancreatitis: a prospective, randomized, double-blind, controlled trial. Pancreas 2011; 40: $181-186$

65 Shao $L$, Chen $Q$, Chen $M$ et al. Nitroglycerin in the prevention of postERCP pancreatitis: a meta-analysis. Dig Dis Sci 2010; 55: 1 - 7

66 Bang UC, Nøjgaard C, Andersen PK et al. Meta-analysis: nitroglycerin for prevention of post-ERCP pancreatitis. Aliment Pharmacol Ther 2009; 29: $1078-1085$

67 Gorelick A, Barnett J, Chey $W$ et al. Botulinum toxin injection after biliary sphincterotomy. Endoscopy 2004; 36: 170-173

68 Matsushita M, Takakuwa H, Shimeno $N$ et al. Epinephrine sprayed on the papilla for prevention of post-ERCP pancreatitis. J Gastroenterol 2009; 44: $71-75$

69 Schwartz JJ, Lew RJ, Ahmad NA et al. The effect of lidocaine sprayed on the major duodenal papilla on the frequency of post-ERCP pancreatitis. Gastrointest Endosc 2004; 59: 179-184

70 Prat F, Amaris J, Ducot B et al. Nifedipine for prevention of post-ERCP pancreatitis: a prospective, double-blind randomized study. Gastrointest Endosc 2002; 56: 202 - 208

71 Sand J, Nordback I. Prospective randomized trial of the effect of nifedipine on pancreatic irritation after endoscopic retrograde cholangiopancreatography. Digestion 1993; 54: 105 -111

72 Bai Y, Xu C, Yang X et al. Glyceryl trinitrate for prevention of pancreatitis after endoscopic retrograde cholangiopancreatography: a meta-analysis of randomized, double-blind, placebo-controlled trials. Endoscopy 2009; 41: 690-695

73 Ding J, Jin X, Pan Y et al. Glyceryl trinitrate for prevention of post-ERCP pancreatitis and improve the rate of cannulation: a meta-analysis of prospective, randomized, controlled trials. PloS One 2013; 8: e75645

$74 \mathrm{Xu} L \mathrm{H}$, Qian JB, Gu LG et al. Prevention of post-endoscopic retrograde cholangiopancreatography pancreatitis by epinephrine sprayed on the papilla. J Gastroenterol Hepatol 2011; 26: 1139-1144

75 Akshintala VS, Hutfless SM, Colantuoni E et al. Systematic review with network meta-analysis: pharmacological prophylaxis against postERCP pancreatitis. Aliment Pharmacol Ther 2013; 38: 1325-1337

76 Räty S, Sand J, Pulkkinen M et al. Post-ERCP pancreatitis: reduction by routine antibiotics. J Gastrointest Surg 2001; 5: 339-345 (discussion 345)

77 Wollschläger S, Pätzold K, Bulang T et al. [Effect of preventive selenium administration on development of ERCP-induced acute pancreatitis]. Med Klin (Munich) 1999; 94: 0381 - 83

78 Niederau C, Pohlmann $U$, Lübke $H$ et al. Prophylactic antibiotic treatment in therapeutic or complicated diagnostic ERCP: results of a randomized controlled clinical study. Gastrointest Endosc 1994; 40: 533 537

79 Alveyn CG, Robertson DA, Wright $R$ et al. Prevention of sepsis following endoscopic retrograde cholangiopancreatography. J Hosp Infect 1991; 19: Suppl C $65-70$

80 Buxbaum J, Yan A, Yeh $K$ et al. Aggressive hydration with lactated ringer's solution reduces pancreatitis after endoscopic retrograde cholangiopancreatography. Clin Gastroenterol Hepatol 2014; 12: $303-307$ (e301)

81 Sagi SV, Schmidt S, Fogel E et al. Association of greater intravenous volume infusion with shorter hospitalization for patients with post-ERCP pancreatitis. J Gastroenterol Hepatol 2014; 29: 1316-1320

82 DiMagno MJ, Wamsteker E-J, Maratt J et al. Do larger periprocedural fluid volumes reduce the severity of post-endoscopic retrograde cholangiopancreatography pancreatitis? Pancreas 2014; 43: 642 - 647

83 Bai Y, Gao J, Shi X et al. Prophylactic corticosteroids do not prevent post-ERCP pancreatitis: a meta-analysis of randomized controlled trials. Pancreatology 2008; 8: 504-509
84 Zheng M, Bai J, Yuan B et al. Meta-analysis of prophylactic corticosteroid use in post-ERCP pancreatitis. BMC Gastroenterol 2008; 8: 6 DOI 10.1186/1471-230X-8-6

85 Sherman S, Cheng C-L, Costamagna $G$ et al. Efficacy of recombinant human interleukin-10 in prevention of post-endoscopic retrograde cholangiopancreatography pancreatitis in subjects with increased risk. Pancreas 2009; 38: $267-274$

86 Dumot JA, Conwell DL, Zuccaro G et al. A randomized, double blind study of interleukin 10 for the prevention of ERCP-induced pancreatitis. Am J Gastroenterol 2001; 96: $2098-2102$

87 Devière J, Le Moine O, Van Laethem JL et al. Interleukin 10 reduces the incidence of pancreatitis after therapeutic endoscopic retrograde cholangiopancreatography. Gastroenterology 2001; 120: 498 - 505

88 Barkay O, Niv E, Santo E et al. Low-dose heparin for the prevention of post-ERCP pancreatitis: a randomized placebo-controlled trial. Surg Endosc 2008; 22: 1971 - 1976

89 Rabenstein T, Fischer B, Wiessner Vet al. Low-molecular-weight heparin does not prevent acute post-ERCP pancreatitis. Gastrointest Endosc 2004; 59: 606-613

90 Schwartz JJ, Lew RJ, Ahmad NA et al. The effect of lidocaine sprayed on the major duodenal papilla on the frequency of post-ERCP pancreatitis. Gastrointest Endosc 2004; 59: 179-184

91 Prat F, Amaris J, Ducot B et al. Nifedipine for prevention of post-ERCP pancreatitis: a prospective, double-blind randomized study. Gastrointest Endosc 2002; 56: 202 - 208

92 Sand J, Nordback I. Prospective randomized trial of the effect of nifedipine on pancreatic irritation after endoscopic retrograde cholangiopancreatography. Digestion 1993; 54: 105 - 111

93 Andriulli A, Annese V. Risk of post-endoscopic retrograde cholangiopancreatography pancreatitis and ways to prevent it: old myths, a current need? The case of allopurinol Clin Gastroenterol Hepatol 2008; 6 : $374-376$

94 Bai Y, Gao J, Zhang Wet al. Meta-analysis: allopurinol in the prevention of postendoscopic retrograde cholangiopancreatography pancreatitis. Aliment Pharmacol Ther 2008; 28: 557 - 564

95 Katsinelos P, Kountouras J, Paroutoglou G et al. Intravenous N-acetylcysteine does not prevent post-ERCP pancreatitis. Gastrointest Endosc 2005; 62: $105-111$

96 Lavy A, Karban A, Suissa A et al. Natural beta-carotene for the prevention of post-ERCP pancreatitis. Pancreas 2004; 29: e45-e50

97 Milewski J, Rydzewska G, Degowska $M$ et al. N-acetylcysteine does not prevent post-endoscopic retrograde cholangiopancreatography hyperamylasemia and acute pancreatitis. World J Gastroenterol 2006; 12: 3751 - 3755

98 Zheng $M$, Chen Y, Bai J et al. Meta-analysis of prophylactic allopurinol use in post-endoscopic retrograde cholangiopancreatography pancreatitis. Pancreas 2008; 37: 247-253

$99 \mathrm{Li}$ S, Cao G, Chen X et al. Low-dose heparin in the prevention of post endoscopic retrograde cholangiopancreatography pancreatitis: a systematic review and meta-analysis. Eur J Gastroenterol Hepatol 2012; 24: $477-481$

$100 \mathrm{Gu}$ W-J, Wei C-Y, Yin R-X. Antioxidant supplementation for the prevention of post-endoscopic retrograde cholangiopancreatography pancreatitis: a meta-analysis of randomized controlled trials. Nutr J 2013; $12: 23$

101 Abbasinazari M, Mohammad Alizadeh AH, Moshiri K et al. Does allopurinol prevent post endoscopic retrograde cholangio- pancreatography pancreatitis? A randomized double blind trial Acta Med Iran 2011; 49: $579-583$

102 Andriulli A, Forlano R, Napolitano $G$ et al. Pancreatic duct stents in the prophylaxis of pancreatic damage after endoscopic retrograde cholangiopancreatography: a systematic analysis of benefits and associated risks. Digestion 2007; 75: 156-163

103 Singh $P$, Das A, Isenberg $G$ et al. Does prophylactic pancreatic stent placement reduce the risk of post-ERCP acute pancreatitis? A meta-analysis of controlled trials Gastrointest Endosc 2004; 60: 544- 550

104 Sofuni A, Maguchi H, Itoi T et al. Prophylaxis of post-endoscopic retrograde cholangiopancreatography pancreatitis by an endoscopic pancreatic spontaneous dislodgement stent. Clin Gastroenterol Hepatol 2007; 5: $1339-1346$

105 Das A, Singh P, Sivak MV et al. Pancreatic-stent placement for prevention of post-ERCP pancreatitis: a cost-effectiveness analysis. Gastrointest Endosc 2007; 65: 960 - 968 
106 Mazaki T, Mado K, Masuda $H$ et al. Prophylactic pancreatic stent placement and post-ERCP pancreatitis: an updated meta-analysis. J Gastroenterol 2014; 49: 343 - 355

107 Akbar A, Abu Dayyeh BK, Baron TH et al. Rectal nonsteroidal anti-inflammatory drugs are superior to pancreatic duct stents in preventing pancreatitis after endoscopic retrograde cholangiopancreatography: a network meta-analysis. Clin Gastroenterol Hepatol 2013; 11: $778-783$

108 Afghani E, Akshintala VS, Khashab MA et al. 5-Fr vs. 3-Fr pancreatic stents for the prevention of post-ERCP pancreatitis in high-risk patients: a systematic review and network meta-analysis. Endoscopy 2014; 46: $173-80$

109 Chahal P, Tarnasky PR, Petersen BT et al. Short 5Fr vs long 3Fr pancreatic stents in patients at risk for post-endoscopic retrograde cholangiopancreatography pancreatitis. Clin Gastroenterol Hepatol 2009; 7: 834-839

110 Zolotarevsky E, Fehmi SM, Anderson MA et al. Prophylactic 5-Fr pancreatic duct stents are superior to 3-Fr stents: a randomized controlled trial. Endoscopy 2011; 43: 325 - 330

111 Cha SW, Leung WD, Lehman GA et al. Does leaving a main pancreatic duct stent in place reduce the incidence of precut biliary sphincterotomy-associated pancreatitis? A randomized, prospective study Gastrointest Endosc 2013; 77: 209-216

112 Moffatt DC, Pradermchai K, Avula $\mathrm{H}$ et al. Moderate and severe postendoscopic retrograde cholangiopancreatography pancreatitis despite prophylactic pancreatic stent placement: the effect of early prophylactic pancreatic stent dislodgement. Can J Gastroenterol 2011; 25: $215-219$

113 Rashdan A, Fogel EL, McHenry $L$ et al. Improved stent characteristics for prophylaxis of post-ERCP pancreatitis. Clin Gastroenterol Hepatol 2004: 2: $322-329$

114 Price LH, Brandabur JJ, Kozarek RA et al. Good stents gone bad: endoscopic treatment of proximally migrated pancreatic duct stents. Gastrointest Endosc 2009; 70: 174-179

115 Halttunen J, Meisner S, Aabakken L et al. Difficult cannulation as defined by a prospective study of the Scandinavian Association for Digestive Endoscopy (SADE) in 907 ERCPs. Scand J Gastroenterol 2014; 49: $752-758$

116 Wang P, Li Z-S, Liu F et al. Risk factors for ERCP-related complications: a prospective multicenter study. Am J Gastroenterol 2009; 104: 31 40

117 Wang B, Guo Z, Liu Z et al. Preoperative versus intraoperative endoscopic sphincterotomy in patients with gallbladder and suspected common bile duct stones: system review and meta-analysis. Surg Endosc 2013; 27: 2454-2465

118 Cheon YK, Cho KB, Watkins JL et al. Frequency and severity of postERCP pancreatitis correlated with extent of pancreatic ductal opacification. Gastrointest Endosc 2007; 65: 385-393

119 George S, Kulkarni AA, Stevens $G$ et al. Role of osmolality of contrast media in the development of post-ERCP pancreatitis: a metanalysis. Dig Dis Sci 2004; 49: 503-508

120 Ogawa M, Kawaguchi Y, Kawashima $Y$ et al. A comparison of ionic, monomer, high osmolar contrast media with non-ionic, dimer, isoosmolar contrast media in ERCP. Tokai J Exp Clin Med 2013; 38: $109-113$

121 Cheng $Y$, Xiong X-Z, Wu S-J et al. Carbon dioxide insufflation for endoscopic retrograde cholangiopancreatography: A meta-analysis and systematic review. World J Gastroenterol 2012; 18: 5622 - 5631

122 Shi H, Chen S, Swar G et al. Carbon dioxide insufflation during endoscopic retrograde cholangiopancreatography: a review and meta-analysis. Pancreas 2013; 42: $1093-1100$

$123 \mathrm{Wu} \mathrm{J,} \mathrm{Hu} \mathrm{B.} \mathrm{Carbon} \mathrm{dioxide} \mathrm{insufflation} \mathrm{versus} \mathrm{air} \mathrm{insufflation} \mathrm{during}$ endoscopic retrograde cholangiopancreatography: a meta-analysis. J Interv Gastroenterol 2013; 3: 37-42

124 Janssens F, Deviere J, Eisendrath $P$ et al. Carbon dioxide for gut distension during digestive endoscopy: technique and practice survey. World J Gastroenterol 2009; 15: 1475-1479

125 Cennamo V, Fuccio L, Zagari RM et al. Can a wire-guided cannulation technique increase bile duct cannulation rate and prevent post-ERCP pancreatitis? A meta-analysis of randomized controlled trials Am J Gastroenterol 2009; 104: 2343-2350

126 Cheung J, Tsoi KK, Quan W-L et al. Guidewire versus conventional contrast cannulation of the common bile duct for the prevention of postERCP pancreatitis: a systematic review and meta-analysis. Gastrointest Endosc 2009; 70: 1211 -1219
127 Lee TH, Park DH, Park J-Y et al. Can wire-guided cannulation prevent post-ERCP pancreatitis? A prospective randomized trial Gastrointest Endosc 2009; 69: 444- 449

128 Kawakami H, Maguchi H, Mukai T et al. A multicenter, prospective, randomized study of selective bile duct cannulation performed by multiple endoscopists: the BIDMEN study. Gastrointest Endosc 2012; 75: 362 - 372 (e361)

129 Mariani A, Giussani A, Di Leo M et al. Guidewire biliary cannulation does not reduce post-ERCP pancreatitis compared with the contrast injection technique in low-risk and high-risk patients. Gastrointest Endosc 2012; 75: 339-346

130 Mohammad Alizadeh AH, Afzali ES, Zafar Doagoo S et al. Preventive role of wire-guided cannulation to reduce hyperamylasemia and pancreatitis following endoscopic retrograde cholangiopancreatography. Diagn Ther Endosc 2012; 2012: 821376

131 Kobayashi G, Fujita N, Imaizumi K et al. Wire-guided biliary cannulation technique does not reduce the risk of post-ERCP pancreatitis: multicenter randomized controlled trial. Dig Endosc 2013; 25: 295302

132 Tse F, Yuan $Y$, Moayyedi $P$ et al. Guide wire-assisted cannulation for the prevention of post-ERCP pancreatitis: a systematic review and meta-analysis. Endoscopy 2013; 45: 605-618

133 Rey JF, Beilenhoff U, Neumann CS et al. European Society of Gastrointest Endosc (ESGE) guideline: the use of electrosurgical units. Endoscopy 2010; 42: 764-772

134 Verma D, Kapadia A, Adler DG. Pure versus mixed electrosurgical current for endoscopic biliary sphincterotomy: a meta-analysis of adverse outcomes. Gastrointest Endosc 2007; 66: 283-290

135 Dumonceau J-M, Deviere J, Cremer M. A new method of achieving deep cannulation of the common bile duct during endoscopic retrograde cholangiopancreatography. Endoscopy 1998; 30: S80

136 Gyökeres T, Duhl J, Varsányi M et al. Double guide wire placement for endoscopic pancreaticobiliary procedures. Endoscopy 2003; 35: 95 96

137 Maeda S, Hayashi H, Hosokawa $O$ et al. Prospective randomized pilot trial of selective biliary cannulation using pancreatic guide-wire placement. Endoscopy 2003; 35: $721-724$

138 Herreros de Tejada A, Calleja JL, Diaz G et al. Double-guidewire technique for difficult bile duct cannulation: a multicenter randomized, controlled trial. Gastrointest Endosc 2009; 70: 700 - 709

139 Xinopoulos D, Bassioukas SP, Kypreos D et al. Pancreatic duct guidewire placement for biliary cannulation in a single-session therapeutic ERCP. World J Gastroenterol 2011; 17: 1989-1995

140 Grönroos JM, Vihervaara H, Gullichsen $R$ et al. Double-guidewire-assisted biliary cannulation: experiences from a single tertiary referral center. Surg Endosc 2011; 25: 1599-1602

141 Belverde B, Frattaroli S, Carbone A et al. Double guidewire technique for ERCP in difficult bile cannulation: experience with 121 cases. Ann Ital Chir 2012; 83: 391 - 393

142 Angsuwatcharakon P, Rerknimitr R, Ridtitid $W$ et al. Success rate and cannulation time between precut sphincterotomy and double-guidewire technique in truly difficult biliary cannulation. J Gastroenterol Hepatol 2012; 27: 356-361

143 Yoo YW, Cha S-W, Lee WC et al. Double guidewire technique vs transpancreatic precut sphincterotomy in difficult biliary cannulation. World J Gastroenterol 2013; 19: 108-114

144 Ito K, Horaguchi J, Fujita $N$ et al. Clinical usefulness of double-guidewire technique for difficult biliary cannulation in endoscopic retrograde cholangiopancreatography. Dig Endosc 2014; 26: 442 - 449

145 Tanaka R, Itoi T, Sofuni A et al. Is the double-guidewire technique superior to the pancreatic duct guidewire technique in cases of pancreatic duct opacification? J Gastroenterol Hepatol 2013; 28: 1787 1793

146 Ito K, Fujita N, Noda Yet al. Can pancreatic duct stenting prevent postERCP pancreatitis in patients who undergo pancreatic duct guidewire placement for achieving selective biliary cannulation? A prospective randomized controlled trial J Gastroenterol 2010; 45: 1183-1191

147 Hisa T. Impact of changing our cannulation method on the incidence of post-endoscopic retrograde cholangiopancreatography pancreatitis after pancreatic guidewire placement. World J Gastroenterol 2011; 17: 5289

148 Cennamo V, Fuccio L, Zagari RM et al. Can early precut implementation reduce endoscopic retrograde cholangiopancreatography-related complication risk? Meta-analysis of randomized controlled trials Endoscopy 2010; 42: $381-388$ 
149 Gong B, Hao L, Bie L et al. Does precut technique improve selective bile duct cannulation or increase post-ERCP pancreatitis rate? A meta-analysis of randomized controlled trials Surg Endosc 2010; 24: 2670 2680

150 Katsinelos P, Gkagkalis S, Chatzimavroudis G et al. Comparison of three types of precut technique to achieve common bile duct cannulation: a retrospective analysis of 274 cases. Dig Dis Sci 2012; 57: 3286 3292

151 Lopes L, Dinis-Ribeiro M, Rolanda C. Safety and efficacy of precut needle-knife fistulotomy. Scand J Gastroenterol 2014; 49: 759-765

152 Chan CHY, Brennan FN, Zimmerman MJ et al. Wire assisted transpancreatic septotomy, needle knife precut or both for difficult biliary access. J Gastroenterol Hepatol 2012; 27: 1293 - 1297

153 Wang $P$, Zhang $W$, Liu F et al. Success and complication rates of two precut techniques, transpancreatic sphincterotomy and needle-knife sphincterotomy for bile duct cannulation. J Gastrointest Surg 2010; 14: $697-704$

154 Yasuda I, Tomita E, Enya M et al. Can endoscopic papillary balloon dilation really preserve sphincter of Oddi function? Gut 2001; 49: 686-691

155 Baron TH, Harewood GC. Endoscopic balloon dilation of the biliary sphincter compared to endoscopic biliary sphincterotomy for removal of common bile duct stones during ERCP: a metaanalysis of randomized, controlled trials. Am J Gastroenterol 2004; 99: 1455 - 1460

156 Weinberg BM, Shindy W, Lo S. Endoscopic balloon sphincter dilation (sphincteroplasty) versus sphincterotomy for common bile duct stones. Cochrane Database Syst Rev 2006; 18: CD004890

157 Liu Y, Su P, Lin S et al. Endoscopic papillary balloon dilatation versus endoscopic sphincterotomy in the treatment for choledocholithiasis: a meta-analysis. J Gastroenterol Hepatol 2012; 27: 464-471

158 Liao $W$ - C, Tu Y-K, Wu M-S et al. Balloon dilation with adequate duration is safer than sphincterotomy for extracting bile duct stones: a systematic review and meta-analyses. Clin Gastroenterol Hepatol 2012; 10: 1101 - 1109

159 Liao W-C, Lee C-T, Chang C-Yet al. Randomized trial of 1-minute versus 5 -minute endoscopic balloon dilation for extraction of bile duct stones. Gastrointest Endosc 2010; 72: 1154-1162

160 Zhao H-C. Meta-analysis comparison of endoscopic papillary balloon dilatation and endoscopic sphincteropapillotomy. World J Gastroenterol 2013; 19: $3883-3891$

161 Natsui M, Saito Y, Abe S et al. Long-term outcomes of endoscopic papillary balloon dilation and endoscopic sphincterotomy for bile duct stones. Dig Endosc 2013; 25: 313 - 321

162 Doi S, Yasuda I, Mukai T et al. Comparison of long-term outcomes after endoscopic sphincterotomy versus endoscopic papillary balloon dilation: a propensity score-based cohort analysis. J Gastroenterol 2012; 48: 1090-1096

163 Ersoz G, Tekesin O, Ozutemiz AO et al. Biliary sphincterotomy plus dilation with a large balloon for bile duct stones that are difficult to extract. Gastrointest Endosc 2003; 57: 156-159
164 Attasaranya S, Cheon YK, Vittal H et al. Large-diameter biliary orifice balloon dilation to aid in endoscopic bile duct stone removal: a multicenter series. Gastrointest Endosc 2008; 67: 1046-1052

165 Maydeo A, Bhandari S. Balloon sphincteroplasty for removing difficult bile duct stones. Endoscopy 2007; 39: 958-961

166 Minami A, Hirose S, Nomoto $T$ et al. Small sphincterotomy combined with papillary dilation with large balloon permits retrieval of large stones without mechanical lithotripsy. World J Gastroenterol 2007; 13: $2179-2182$

167 Misra SP, Dwivedi M. Large-diameter balloon dilation after endoscopic sphincterotomy for removal of difficult bile duct stones. Endoscopy 2008; 40: 209-213

$168 \mathrm{Heo} \mathrm{JH}$, Kang DH, Jung HJ et al. Endoscopic sphincterotomy plus largeballoon dilation versus endoscopic sphincterotomy for removal of bile-duct stones. Gastrointest Endosc 2007; 66: 720 - 726 ; quiz 768 , 771

169 Feng Y, Zhu H, Chen X et al. Comparison of endoscopic papillary large balloon dilation and endoscopic sphincterotomy for retrieval of choledocholithiasis: a meta-analysis of randomized controlled trials. J Gastroenterol 2012; 47: 655-663

$170 \mathrm{Kim} \mathrm{TH,} \mathrm{Oh} \mathrm{HJ,} \mathrm{Lee} \mathrm{JY} \mathrm{et} \mathrm{al.} \mathrm{Can} \mathrm{a} \mathrm{small} \mathrm{endoscopic} \mathrm{sphincterotomy}$ plus a large-balloon dilation reduce the use of mechanical lithotripsy in patients with large bile duct stones? Surg Endosc 2011; 25: 3330 3337

171 Liu Y, Su P, Lin Y et al. Endoscopic sphincterotomy plus balloon dilation versus endoscopic sphincterotomy for choledocholithiasis: A meta-analysis. J Gastroenterol Hepatol 2013; 28: 937-945

172 Madhoun MF, Wani S, Hong S et al. Endoscopic papillary large balloon dilation reduces the need for mechanical lithotripsy in patients with large bile duct stones: a systematic review and meta-analysis. Diagn Ther Endosc 2014; 2014: 1 -8

173 Singh P, Gurudu SR, Davidoff S et al. Sphincter of Oddi manometry does not predispose to post-ERCP acute pancreatitis. Gastrointest Endosc 2004; 59: 499-505

174 Sherman S, Hawes RH, Troiano FP et al. Pancreatitis following bile duct sphincter of Oddi manometry: utility of the aspirating catheter. Gastrointest Endosc 1992; 38: 347-350

175 Pfau PR, Banerjee S, Barth BA et al. Sphincter of Oddi manometry. Gastrointest Endosc 2011; 74: 1175-1180

176 Saad AM, Fogel EL, McHenry L et al. Pancreatic duct stent placement prevents post-ERCP pancreatitis in patients with suspected sphincter of Oddi dysfunction but normal manometry results. Gastrointest Endosc 2008; 67: 255-261

177 Kaffes AJ, Sriram PVJ, Rao GV et al. Early institution of pre-cutting for difficult biliary cannulation: a prospective study comparing conventional vs. a modified technique. Gastrointest Endosc 2005; 62: 669 674 